\title{
The effects of surface texture in reciprocating contacts - an experimental study
}

\author{
Sorin-Cristian Vladescu ${ }^{a, *}$, Andrew V. Olver ${ }^{a}$, Ian G.Pegg ${ }^{b}$, Tom Reddyhoff ${ }^{a}$ \\ ${ }^{a}$ Tribology Group, Department of Mechanical Engineering, Imperial College London, South Kensington, Exhibition \\ Road, SW7 2AZ, London, United Kingdom \\ ${ }^{\mathrm{b}}$ Ford Motor Company, Dunton, Essex, United Kingdom \\ * Corresponding author. Tel.: +44 (0) 2075947236 \\ E-mail address: s.vladescu12@imperial.ac.uk
}

\begin{abstract}
The effect of surface texture on friction has been investigated experimentally for a convergentdivergent bearing, operating under different lubrication regimes. This was achieved using recently developed test apparatus that closely simulates an automotive piston ring-liner contact, by sliding patterned plane fused silica surfaces against a convex steel pad. Textured patterns, consisting of pockets of varying shapes and orientations, were assessed on their ability to reduce frictional losses, and results compared with those from a reference smooth surface. These tests were performed under a range of lubricant viscosities and applied normal loads in order to vary lambda values (i.e. the ratio of minimum film thickness to composite roughness) and hence highlight the beneficial or detrimental effects of texture in boundary, mixed and full film regimes. In the boundary and mixed regimes - the regimes where surface texture was beneficial - grooves normal to the sliding direction were the most effective patterns among those investigated, reducing friction by up to $62 \%$. The results suggest that pockets act to increase fluid entrainment and hence reduce any asperity contact that is present. However, pockets at reversal were shown to increase friction dramatically. In the full film regime, when a liquid film fully separates sliding surfaces, texture was shown to increase friction compared to the smooth case. In addition to this, the experimental setup allowed cavitation in the ring-liner pairing to be imaged. These results may suggest that the increase in full film friction due to surface texture may be due to the interaction of pockets with the cavitated region. Furthermore, imaging results confirm previous research in that the number of cavitation streamers increase as the film thickness decreases.
\end{abstract}

Keywords: Surface Texture, Surface patterning, Piston rings, Lubrication, Cavitation, Friction

\section{Introduction}

In recent years, interest in reducing friction in internal combustion (IC) engines has grown significantly. This has mainly been due to stricter emission standards. For instance, in 2009, the European Union (EU) introduced an average $\mathrm{CO}_{2}$ emission limit of $130 \mathrm{~g} / \mathrm{km}$ for new models of passenger car, to be achieved by 2015 [1]. Furthermore, from 2020 onwards, EU regulations set a target of $95 \mathrm{~g}$ of $\mathrm{CO}_{2} / \mathrm{km}$ as the average emissions for the new car fleet [2]. As a result, motor vehicle manufacturers have been increasing their investment in energy efficient technologies, to reduce fuel consumption and consequently $\mathrm{CO}_{2}$ emissions. As part of the drive to meet these increasingly strict standards, there is now a heavy focus on the reduction of friction between the piston rings and cylinder liners.

According to Holmberg et al. in [3] , IC engines exhibit considerable energy losses, with a significant proportion $(11.5 \%)$ of the total dissipated fuel energy being due to engine friction. 
Furthermore, based on data gathered from various studies, Holmberg [3] concluded that the piston/cylinder system accounts for $45 \%$ of the IC engine friction loses, of which $40-45 \%$ come from the piston [4].

It is predominantly for these reasons that the concern of reducing friction in the piston ringliner conjunction has received considerable attention in the academic literature, with key issues such as surface texture being extensively investigated. Although many studies have suggested that surface texturing can positively influence load support capabilities, friction and wear, the exact geometric parameters and operating conditions which enhance load carrying capacity or increase film thickness are yet to be demonstrated. To address this, the current paper describes research, using a newly developed experimental set-up, into textured bearings under reciprocating motion, simulating the contact between a piston ring and a cylinder liner. The impact of surface texture geometry on friction force is assessed for three distinct lubrication regimes: boundary, mixed and full film. Moreover, the study experimentally investigates the effects of cavitation in the ring-liner pairing, in order to assess the underlying mechanisms for textured and non-textured specimens.

\section{Background}

There has been widespread interest in the last half century in the study of microtexturing bearing surfaces. The concept that surface 'micro-irregularities' may have an advantageous impact on friction between moving surfaces was introduced by Hamilton, Allen and co-workers in the mid 1960s [ $[\underline{5}, \underline{6}]$. They pointed out that the addition of 'asperities and depressions' to one face of a parallel rotary-shaft face seal can improve the load support capabilities of the seal. Nevertheless, the vast majority of research investigating the performances of textured bearings was carried out in the last two decades. The study of micropockets was brought back in focus by Tonder $[\underline{7}, \underline{8}]$ who primarily researched the effects of texture addition to both moving and stationary bearing surfaces. His research showed that the optimal positioning of the texture is in the vicinity of the bearing's inlet. Two phenomena were indicated as potential explanations. On the one hand, the texture reduces fluid leakage from the contact by creating resistance. On the other, a "virtual step" is created, similar to the abrupt change in film thickness used in Rayleigh step bearings.

Etsion and co-workers have several contributions to the field of laser applied microtexture. For almost a decade, they have experimented with, and theorised on, a wide variety of bearing geometries and rig settings [9-12]. Moreover, Etsion provided the academic community with a comprehensive review on the subject of laser surface texturing (LST) [13]. Experimenting with parallel bearings in reciprocating motion under pure sliding conditions, it was demonstrated that certain micropocket geometries can reduce friction by up to $40 \%$. Particularly interesting was the behaviour of deep pockets, which showed poor performance, explained by the higher quantity of oil needed to maintain hydrodynamic film thickness at the onset of starvation.

One of the most important conclusions of Etsion's experiments is that a multitude of codependent parameters contribute to friction reduction in microtextured bearings. The interdependency of these variables was later extensively investigated by Fowell [14].

Despite its influential contribution, Etsion's numerical work [9-12] was limited by mass conserving considerations. Ausas et al. $[\underline{15}, \underline{16}]$ and Fowell $[\underline{17}, \underline{18}]$ refined his theoretical approach using a mass conserving cavitation algorithm, and demonstrated that load support had been overpredicted in Etsion's non-mass conserving approach, leading to exaggeratedly low values of friction coefficient. 
Ryk et al. [19, 20] made further extensive experimental contribution regarding the effect of textured surfaces in reciprocating piston ring/liner interfaces. Test rig experiments were conducted to evaluate the reduction in friction for non-textured versus textured and partially textured piston rings, when in contact with cylinder liner segments. The authors concluded that, by partially laser surface texturing the piston-rings at both axial ends, friction reduction of up to $25 \%$ can be achieved in comparison with the non-textured reference specimens.

Valuable experimental work on reducing frictional losses in IC engines by using laser-etched texture was also carried out by Rahnejat et al. [21]. The group used a single-cylinder test engine to study variations in torque for three cylinder liner configurations: a standard liner, a diamond-like carbon (DLC) coated liner and a laser-etched textured liner. Improvements of up to $4.5 \%$ could be observed when using the laser-etched textured liner, compared to the standard liner.

Subsequent experiments by Costa et al. [22] employed a capacitance technique to measure the minimum film thickness in a reciprocating contact with one surface containing a micro-textured pattern. Several pattern types were tested and it was concluded that for a given load the addition of specific texture patterns can increase the minimum film thickness in the reciprocating contact. However, this observation cannot be generalised, as situations where texturing can be disadvantageous to lubricant film formation were also demonstrated, particularly at very low loads. Experiments showed that the shape and orientation of patterns has a direct influence on film thickness, with chevron patterns pointing along the sliding direction being most effective configuration. Conversely, measurements using grooved textures gave the lowest fluid film thickness. Another noteworthy observation form their work was that features larger than the elastic contact width resulted in lower film thickness values when compared to smooth test samples.

More recently, dynamometer tests were carried out on a real IC engine, as described by Etsion et al. [23]. A naturally aspired $2,500 \mathrm{~cm}^{3}$ Ford Transit engine was used to evaluate the effect on fuel consumption of laser surface texturing, being partially applied to the upper set of piston rings. Under these conditions, it was discovered that fuel consumption for partially LST chrome coated piston rings was up to $4 \%$ lower than in the case of corresponding non-textured conventional barrel-shaped piston rings. The effect of LST on the exhaust gas composition was also investigated; however, no significant difference between textured and non-textured piston rings was observed.

Other recent experimental work has been reported by Podgornik et al. [24], in which friction force in a lubricated contact was measured by using a piezoelectric friction transducer. Various patterned surfaces, comprising semi-circular grooves and dimples, were tested at different sliding speeds. It was observed that, given the correct geometric features of the pattern (pocket width and distance between pockets), reductions in the friction coefficient of between $20 \%$ and $40 \%$ can be achieved.

In conclusion, by reviewing the most relevant experimental results in the area of microtexturing bearing surfaces reported over the last half century, it becomes evident that the addition of texture can have both beneficial and detrimental effects on friction reduction. Greater load support and/or thicker lubricating film values were reported when testing bearing surfaces with specific micro textured patterns. Despite these achievements, most of the previous experimental work was limited by an exclusive focus on the impact of patterns on friction reduction, i.e. the shape of texture features and the geometric parameters of the pockets. In the process, the importance of, and interactions between, all the variables and operating conditions involved in the 
study of plain and micro-textured convergent-divergent contacts have so far been somewhat overlooked.

The current research attempts to addresses the aforementioned shortcoming to a large extent, by employing a reciprocating rig capable of measuring friction force and film thickness in situ and simultaneously, as well as cavitation in plain and textured contacts. Furthermore and perhaps most importantly, the tests are performed while accurately controlling all operating conditions at all times.

\section{Description of experimental apparatus}

A specially designed reciprocating optical test rig was developed to allow for the simultaneous measurement of friction, film thickness and cavitation behaviour in lubricated smooth and textured surfaces. The study investigates friction and cavitation behaviour associated with the contact between the liner and the piston's top ring, aiming to closely replicate the interaction between the two elements inside an engine. The most significant limitation is the use of a single ring, whereas pistons in IC engines commonly have three and in some cases more rings. Moreover, the piston skirt comes in direct contact with the liner in the real scenario [25]. In addition to this, the stroke length used in this study is $26.8 \mathrm{~mm}$, which is shorter than in a typical engine, however this is unlikely to affect the results obtained. In other respects however, the rig accurately replicates piston liner contact conditions.

Measurements of friction between the contacting surfaces - a convex AISI 52100 steel pad with a width of $2 \mathrm{~mm}$ and the counterpart fused silica specimen - are achieved by employing a low capacity isometric load cell, permanently in direct contact with a special holder mechanism. This holder mechanism was designed to allow for the measurement of friction force on the one hand, and the self-alignment of the steel test specimen on the other.

The silica plate, simulating the cylinder liner of an IC engine, reciprocates relative to the steel specimen, via a cam mechanism responsible for controlling amplitude and sinusoidal velocity profile, thus accurately replicating the piston's motion. Two steel shims allow for the displacement of the upper part of the specimen holder away from or towards the load cell. As the specimen holder deflects due to friction forces in the reciprocating contact, a voltage differential is recorded, proportional with the specimen deflection. The main structural features of the friction measurement mechanism are shown in Figure 1.

The reciprocal motion of the fused silica pad along two linear bearings is ensured by an electric motor which drives the adjustable stroke cam mechanism. A continuous and smooth sliding movement of the silica plate at both ends of the stroke is ensured by employing two centrifugal governors. As a result of governor inertia, the silica plate holder is forced to continue its reciprocating motion every time one of the dead centres is reached, changing its direction. 


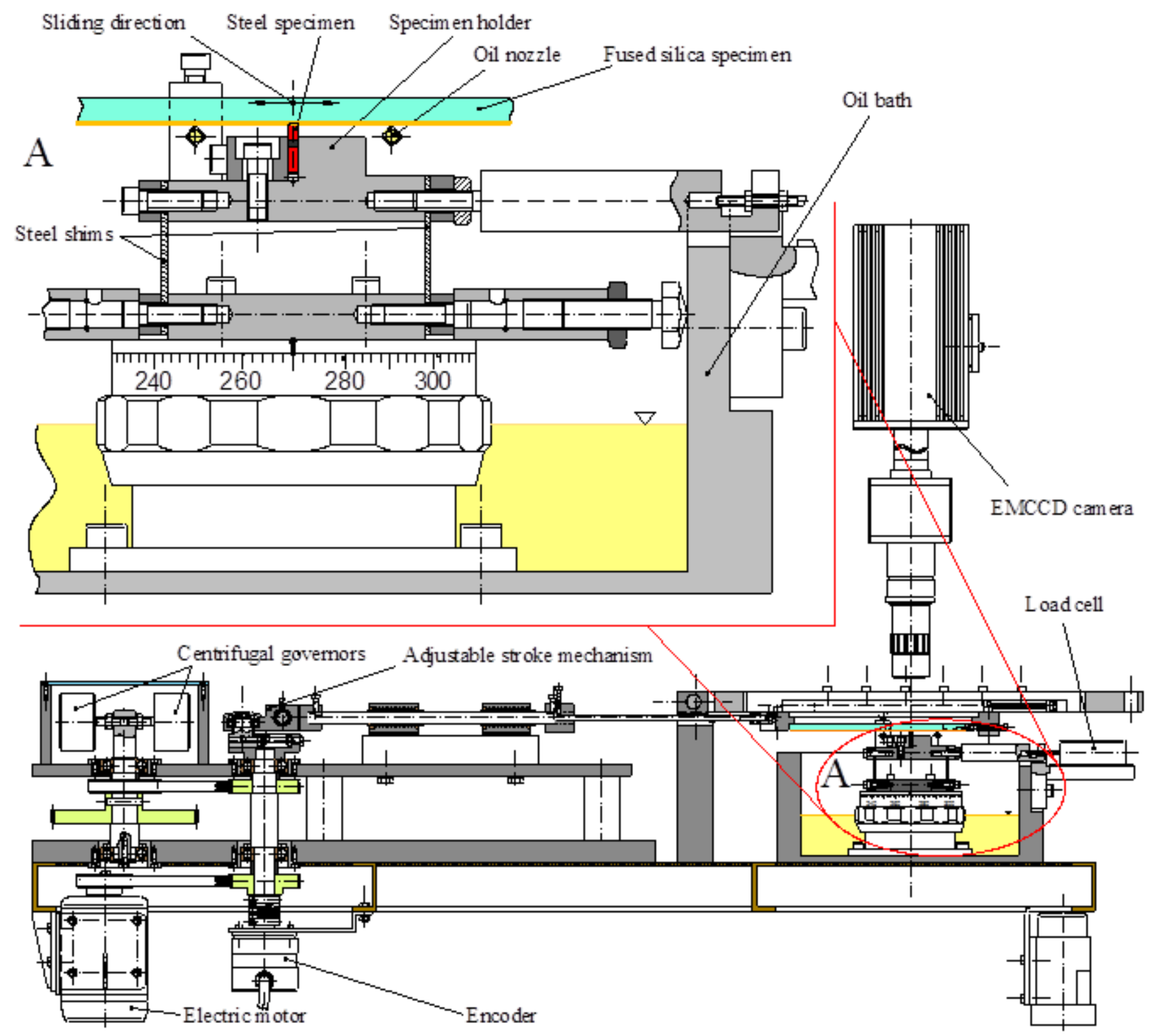

Figure 1 - Schematic representation of the reciprocating test rig.

The reciprocating speed is measured by a 9 bit rotary position encoder, fixed securely to the bottom of the cam mechanisms' shaft and used to determine both the angular position and velocity of the shaft.

The oil is supplied directly to each side of the contact area by using two nozzles, attached to the oil bath. This arrangement prevents inlet starvation, supplying a sufficient rate of SAE 40 fully formulated oil to the reciprocating contact. Initial experimental tests revealed that the most critical operating parameter is the oil temperature. Even a slight change in the oil temperature, and consequently in its viscosity, is liable to dramatically alter the measured of friction values. It is for this reason that the oil supply system was carefully designed to accurately control the oil temperature over a large range. More precisely, a Thermo Scientific SC150 immersion circulator was installed in the reciprocating rig system to precisely control the oil temperature between $+10^{\circ} \mathrm{C}$ and $+150^{\circ} \mathrm{C}$ with a temperature stability of $0.02^{\circ} \mathrm{C}$. A Cole-Parmer gear pump is used to transport the oil from the immersion circulator to the reciprocating contact while at the same time controlling the oil flow rate. Finally, an additional peristaltic pump is employed to return the oil from the rig's 
oil bath to the immersion circulator. The oil heating control temperature setup allows the assessment of textured and non-textured bearing configurations to be carried out under all lubrication regimes: boundary, mixed and full film.

An operating normal load (W) is applied by means of dead weights attached to the silica pad specimen holder.

For a precise visualization of cavitation and an accurate evaluation of its pattern, an optical technique based on Laser Induced Fluorescence, LIF, (i.e. the photo-excitation of a fluorescent dye) was built onto the reciprocating rig. In addition to measuring cavitation, the LIF system provides a secondary film thickness assessment to complement measurements achieved using optical interferometry (this will be carried out in future work). Moreover, the latter technique enables observation of distinct pockets passing through contact.

In order to image texture moving through the contact and evaluate cavitation precisely in the vicinity of end strokes, a 9 bit trigger system was designed and manufactured. This electronic circuit enables both the high-speed camera used for interferometry measurements, and the EMCCD camera used for fluorescence measurements, to be triggered with precision equal to 0.7 degrees of crankshaft revolution. Visual proof of the accuracy of the trigger system is shown in Figure 2, where four captured images are at the same triggering point over four consecutive reciprocating strokes of the silica plate. Evident in the top left corner of the figure are two small cavitation streamers, captured each time in the exact same location.

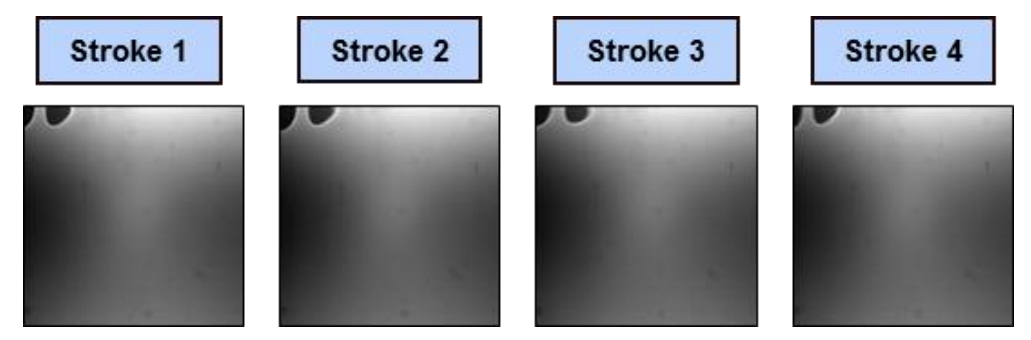

Figure 2 - Four different cavitation images captured at the same triggering point over four different strokes.

The most important feature of the 9 bit trigger system is that it enables the observer to accurately identify the film thickness and frictional response for individual textured and nontextured specimens, at any distinct point along the stroke of the pad. As shown in Section 6, this allows friction force to be plotted against stroke angle.

\section{Specimens and experimental procedure}

The experimental tests use an AISI 52100 steel specimen, closely replicating an IC engine piston ring. The initial, fully hardened $(850 \mathrm{HV})$, specimen had all surfaces ground and a minimum stock of $0.15 \mathrm{~mm}$ removed, to achieve a $10 \times 10 \times 2 \mathrm{~mm}$ rectangular pad. Subsequently, the side with a $2 \mathrm{~mm}$ width was ground at a $40 \mathrm{~mm}$ radius, curved in the sliding direction to result in a convergent-divergent form. A high degree of emphasis was placed on mirror-polishing the convex surface of the steel test pad accurately, this procedure being crucial to film thickness measurements and fluorescence observation. A high quality of the polished surface and an accurate radius along the pad's length were obtained (as depicted in Figure 3) by employing a specially designed jig in conjunction with a $0.25 \mu \mathrm{m}$ monocrystalline water based diamond spray. 


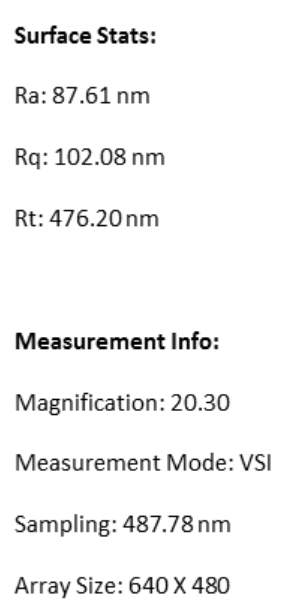

Array Size: $640 \times 480$

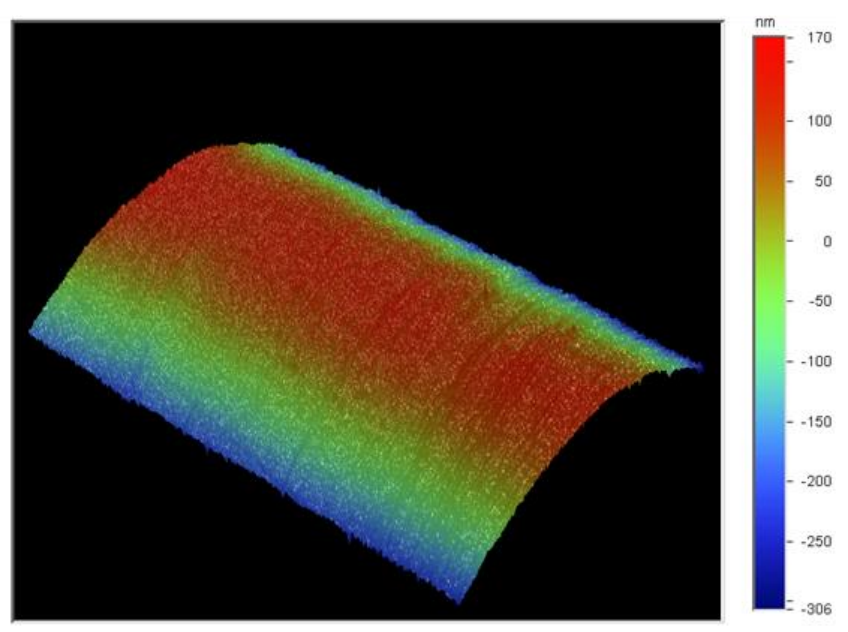

Figure 3 - Three dimensional surface plot of a convex AISI 52100 steel specimen; roughness average $\mathrm{Ra}=88 \mathrm{~nm}$, curvature radius $40 \mathrm{~mm}$.

The counterpart specimens were manufactured from a HPFS Standard Grade fused silica material, due to its elastic modulus $(72.7 \mathrm{GPa})$ being higher than normal glass for improved friction measurement, and its excellent optical qualities for improved fluorescence image quality.

Various textured patterns and pocket shapes were tested in the initial phase of the research, on the basis of expert advice received from computational collaborators [14]. The criteria for the selection were (1) the predicted increase in load support and (2) the hypothesised decrease in friction.

The surface texturing was performed on the $125 \times 15 \times 5 \mathrm{~mm}$ rectangular fused silica specimens using an ultrafast picosecond laser, emitting optical pulses with a duration of 10 picoseconds. The other performance parameters selected for the laser texturing were: frequency of $10 \mathrm{kHz}$, wavelength of $355 \mathrm{~nm}$, power of 5 micro joules. The smooth fused silica pad had the same outer dimensions as the textured specimens.

Geometries displaying identical features repeated at regular intervals were laser textured for a variety of distinct shapes. The pocket depth was largely maintained constant for a more accurate comparison between different shapes. Figure 4 shows the three-dimensional optical profiles of the textured and non-textured samples as recorded by the Veeco Wyko NT9100 optical profiler. The five pocketed fused silica specimens selected for this research are further detailed in Table 1. 

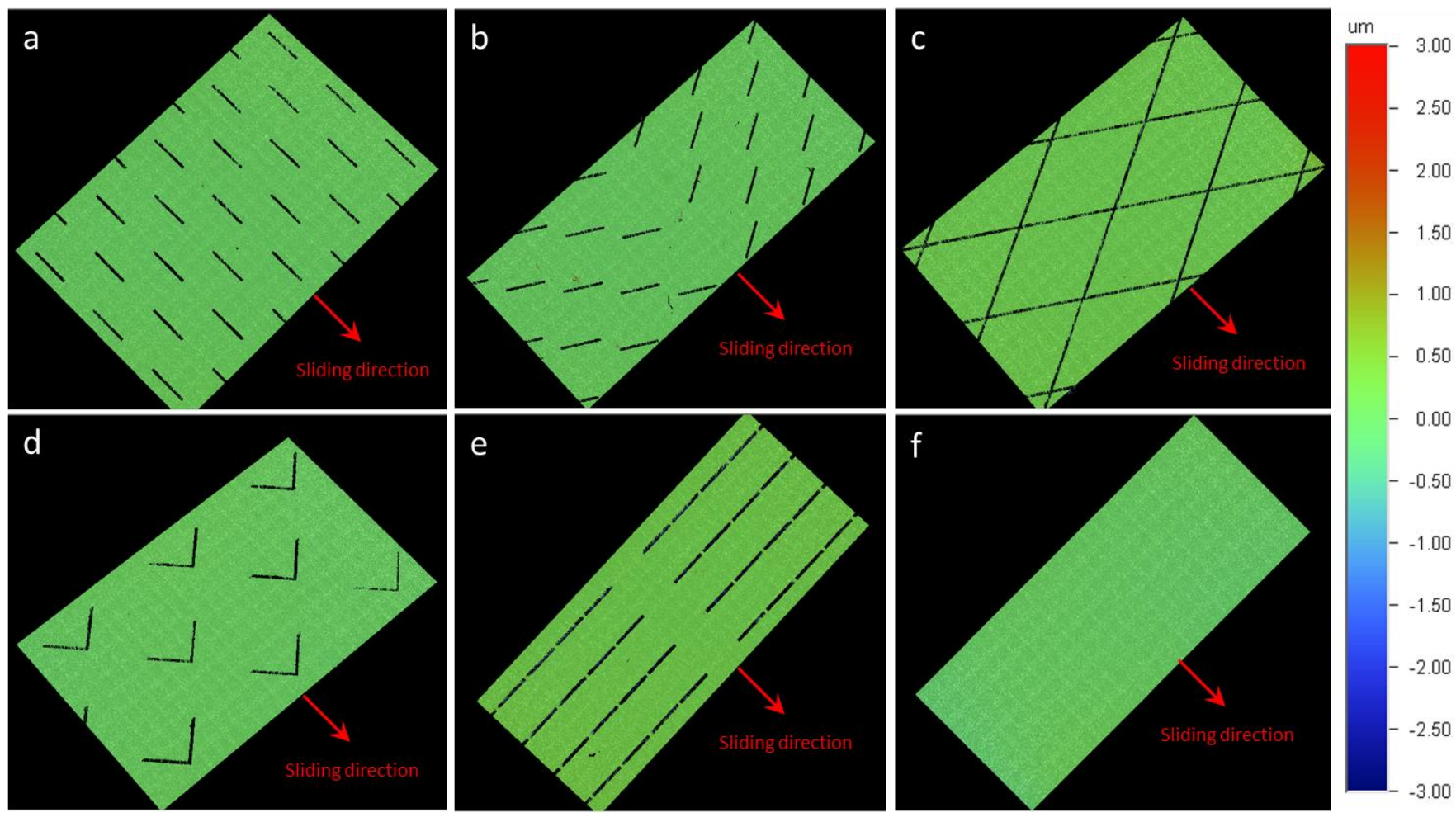

Figure 4 - Three dimensional surface plots of fused silica specimens with different textured patterns: (a) Parallel Grooves - PlG; (b) Angular Grooves - AnG; (c) Crosshatch - Xh; (d) Chevrons - ChV; (e) Transverse Grooves - TrG; (f) Smooth.

Table 1 - Geometric parameters of the pocketed fused silica specimens

\section{Sample shape}

Chevron Angular Grooves

Both prior to the beginning and after the testing sequence, accurate calibrations of the isometric load cell were carried out. To achieve this, a series of known masses were used to displace the steel pad holder in both tangential directions (tension/compression) so as to accurately define the 
relationship between distance travelled by the pad holder and equivalent voltage. During the calibration, voltages are recorded as the sensor was loaded and unloaded in both tension and compression. The average values obtained from this procedure, are used to determine the equation relating voltage output to frictional force.

Reciprocating sliding tests were conducted to compare the plain and textured silica pads sliding against the mirror finish stationary steel pad counterpart, while varying engine speed and applied load. The relative reciprocating motion between the two counter-bodies takes place with a controlled amplitude (stroke length) of $28.6 \mathrm{~mm}$.

Tests were repeated while controlling the temperature, and consequently the viscosity, of the fully formulated oil. Table 2 shows the complete range of temperatures and the corresponding viscosities used to perform tests, as well as the computed values for mid-stroke film thickness and lambda ratio, for a convergent-divergent non-textured bearing of identical geometry. Prior to film thickness calculation, Johnson's method [26] for a line contact was employed to determine which type of contact condition applies for each case. This showed that for all three test temperatures the contact operates under elastic-piezoviscous conditions. By consequently assuming both elastic deformation and lubricant pressure-viscosity increases, mid-stroke film thickness was calculated using Dowson and Higginson's equation for a line contact. The determined values of film thickness were used to finally calculate the three lambda values shown in Table 2, which suggest that the contact will be operating in either the boundary, mixed or full film regime, depending on oil temperature. For the purposes of the following discussion, the contact conditions are referred to by these calculated lambda values: $\lambda=0.9$ signifies the boundary regime, $\lambda=2.2$ the mixed regime, and $\lambda=6.4$ the full film lubrication regime. It should be noted that these values are approximate since they pertain only to smooth case - the exact film thickness in the textured contact being unknown.

\begin{tabular}{|c|c|c|c|c|c|c|c|}
\hline \multirow[b]{2}{*}{$\begin{array}{l}\text { Load, } \\
\text { W [N] }\end{array}$} & \multirow{2}{*}{$\begin{array}{c}\text { Crank } \\
\text { angular } \\
\text { velocity, } \\
\text { [rpm] }\end{array}$} & \multirow[b]{2}{*}{$\begin{array}{c}\text { Oil } \\
\text { Temperature } \\
{\left[{ }^{\circ} \mathrm{C}\right]}\end{array}$} & \multicolumn{3}{|c|}{ Oil properties } & \multirow{2}{*}{$\begin{array}{c}\text { Film } \\
\text { thickness } \\
\text { (mid-stroke), } \\
\mathbf{h}_{\mathbf{0}}[\mathrm{nm}]\end{array}$} & \multirow[b]{2}{*}{$\begin{array}{c}\text { Lambda } \\
\text { Ratio, } \\
\Lambda[-]\end{array}$} \\
\hline & & & $\begin{array}{c}\text { Dynamic } \\
\text { viscosity, } \eta \\
\text { [mPa:s] }\end{array}$ & $\begin{array}{c}\text { Kinematic } \\
\text { viscosity, v } \\
{\left[\mathrm{mm}^{2} / \mathrm{s}\right]}\end{array}$ & $\begin{array}{c}\text { Density, } \rho \\
{\left[\mathrm{g} / \mathrm{cm}^{3}\right]}\end{array}$ & & \\
\hline \multirow{3}{*}{50} & \multirow{3}{*}{180} & 15 & 273.628 & 314.913 & 0.8689 & 573.3 & 6.4 \\
\hline & & 45 & 61.727 & 72.603 & 0.8502 & 202.2 & 2.2 \\
\hline & & 80 & 18.847 & 22.753 & 0.8283 & 88.1 & 0.9 \\
\hline
\end{tabular}

Table 2 - Properties of the fully engine formulated oil at the desired temperatures used during the test session, along with calculated film thickness and lambda ratio for the untextured contact at mid-stroke.

Frictional force between steel pad and moving fused silica pad was acquired, using a specially developed LabVIEW program. In situ, cavitation zones were recorded concurrently with friction using the LIF observation technique.

Prior to commencing the testing sequence, frictional force stability over time and repeatability between tests was assessed and confirmed. Figure 5 shows the repeatability of friction measurements for the smooth specimen, over three non-consecutive testing sessions, for one combination of test conditions (crank angular velocity: $180 \mathrm{rpm}$, normal load: $50 \mathrm{~N}$, oil temperature: $80^{\circ} \mathrm{C}$ ). Although this figure shows only smooth surface results, it should be noted that tests with textured specimens showed the same level of repeatability. 


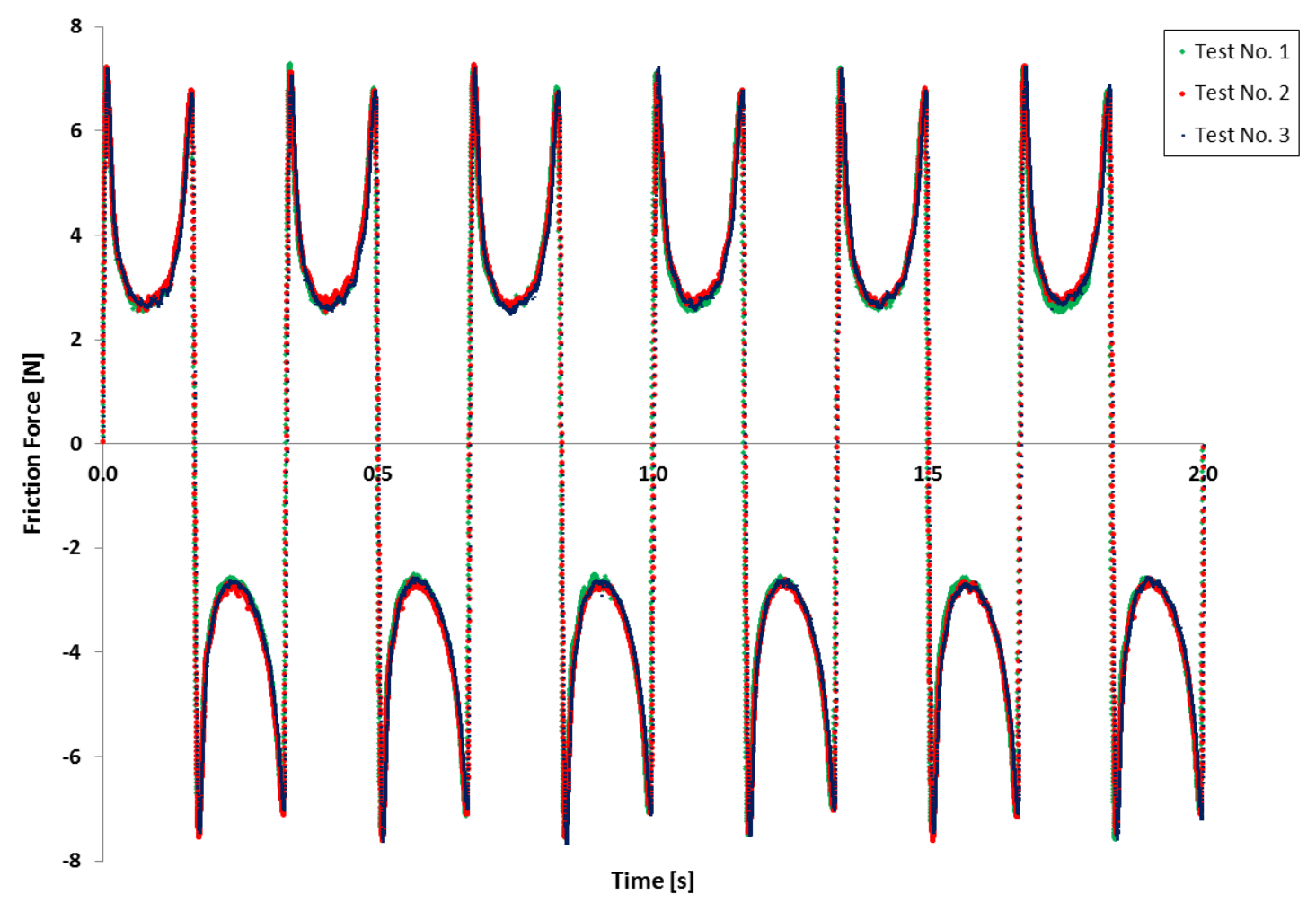

Figure 5 - Stable friction force versus time for the smooth specimen; repeatability between different tests.

\section{Results}

Multiple series of friction tests were carried out for all five textured configurations and the nontextured reference pad. The results are graphically depicted for various engine speeds, applied loads and oil viscosities, with the extent of friction reduction resulting from the various pocketed surfaces being analysed for each different test condition.

Figures 6,7 and 8 show the friction force variation when the contact is operating in the full film, mixed and boundary lubrication regime respectively. In each case the effects of the various textured pattern shapes on friction force are compared to the smooth case. Figure 9 summarises the change in friction force over a complete cycle for every regime.

The textured-to-smooth difference is further investigated for a range of normal loads, varying from 10 to $100 \mathrm{~N}$, passing through the three lubrication regimes. The resulting performances of each surface texture shape are finally shown together in Figure 10. This graph also enables performance comparison between different pattern orientations, for grooves positioned perpendicular, parallel and at a 60 degree angle relative to the sliding direction.

Figure 13 shows friction force variation with velocity along the stroke over one full cycle. The resulting curves for smooth and transverse grooves textured (pattern $\mathrm{TrG}$ ) specimens are plotted for the three lubrication regimes. The positioning of the texture along the length of the stroke was also investigated. This was achieved by comparing friction force measurements for a specimen textured along the entire sliding distance and one textured in the central region but with a smooth section at the end-stroke, as depicted in Figure 12.

Finally, zones of cavitation were observed throughout the reciprocating tests, using the fluorescence technique described previously. An example showing the variation in the cavitation pattern with normal load for the smooth specimen is presented in Figure 14. 


\section{Discussion}

\subsection{Influence of surface texture under various bearings' lubrication regimes}

The issue of reducing friction in reciprocating sliding bearings has received a great deal of attention in the literature, with key issues such as surface texture being extensively investigated. However, the vast majority of previous studies were performed considering only one lubrication regime, the hydrodynamic lubrication regime.

To address this limitation, the research in the current paper places a great degree of emphasis on experimentally obtaining the distinct variations in friction force that occur when the convergentdivergent sliding bearing is operating in different lubrication regimes. Therefore, the primary purpose of the study is to determine the lubrication regime under which surface texture is beneficial to friction force reduction and load carrying capability.

Figures 6-8 show the relationship between friction force and stroke angle, for a constant crank angular velocity of $180 \mathrm{rev} / \mathrm{min}$ and a normal load of $50 \mathrm{~N}$. The only variation in test conditions is the oil temperature (and consequently oil viscosity), which is $15^{\circ} \mathrm{C}, 45^{\circ} \mathrm{C}$ and $80^{\circ} \mathrm{C}$ respectively (see Table 2). Friction force graphs are plotted for two complete revolutions of the adjustable stroke rotating mechanism (equivalent to four strokes of the silica pad)

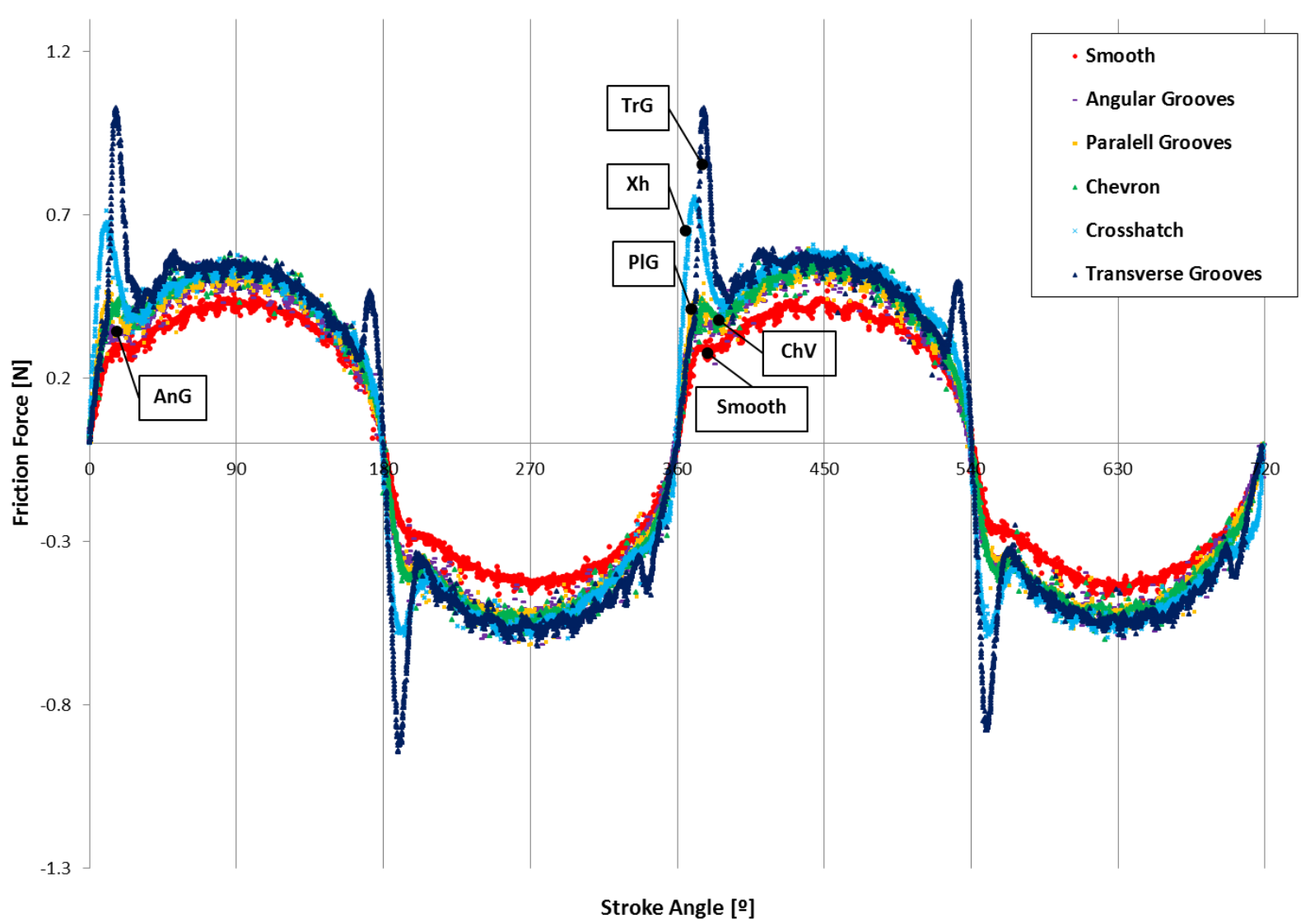

Figure 6 - Friction force comparison between all textured and non-textured samples under the full film lubrication regime (test conditions: crank angular velocity: $180 \mathrm{rpm}$, normal load: $50 \mathrm{~N}$, oil temperature: $15^{\circ} \mathrm{C}, \lambda_{\text {smooth,mid-stroke }}=$ 6.4). 


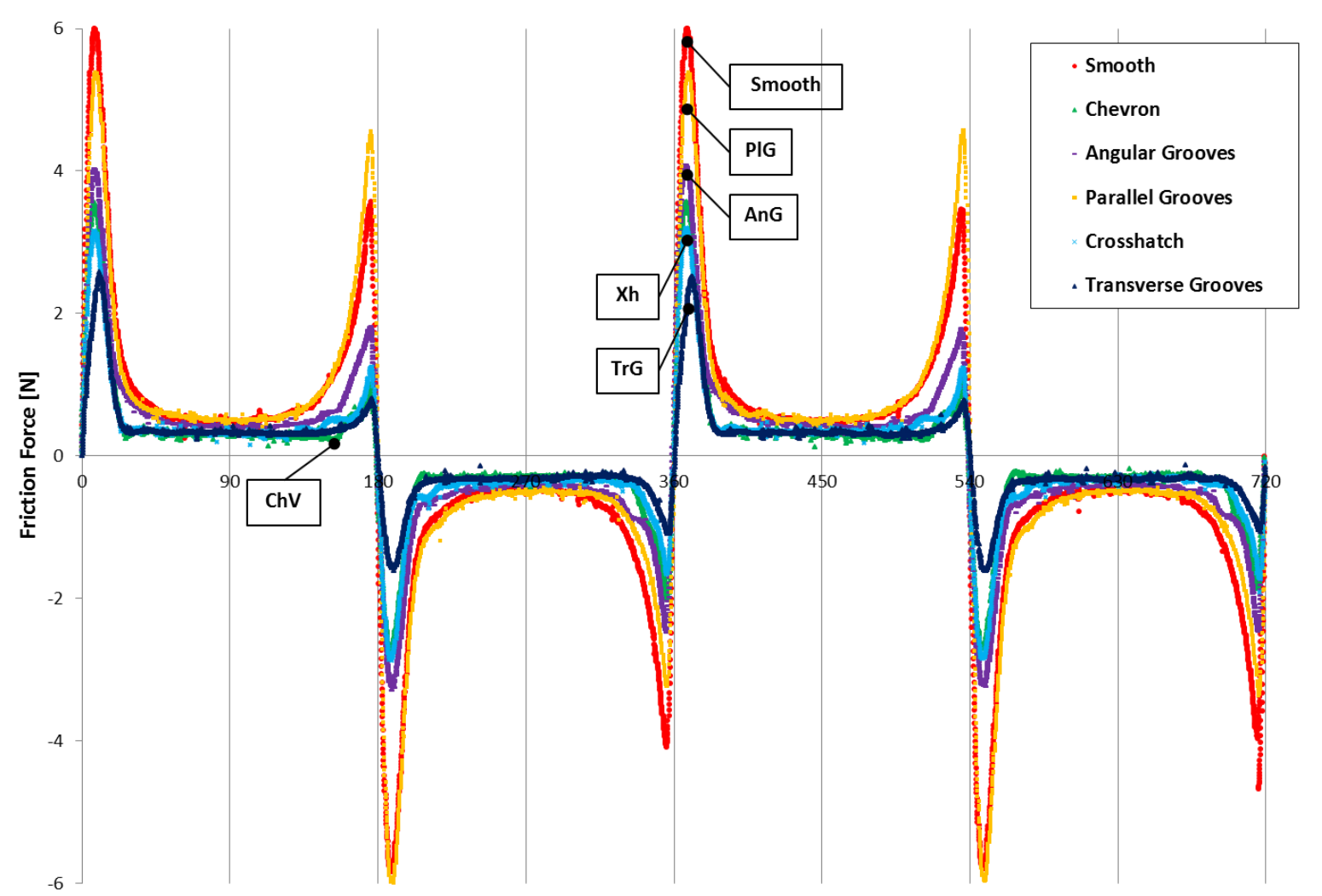

Stroke Angle [ㅇ]

Figure 7 - Friction force comparison between textured and non-textured samples under the mixed lubrication regime (test conditions: crank angular velocity: $180 \mathrm{rpm}$, normal load: $50 \mathrm{~N}$, oil temperature: $45^{\circ} \mathrm{C}, \lambda_{\text {smooth mid-stroke }}=2.2$ ).

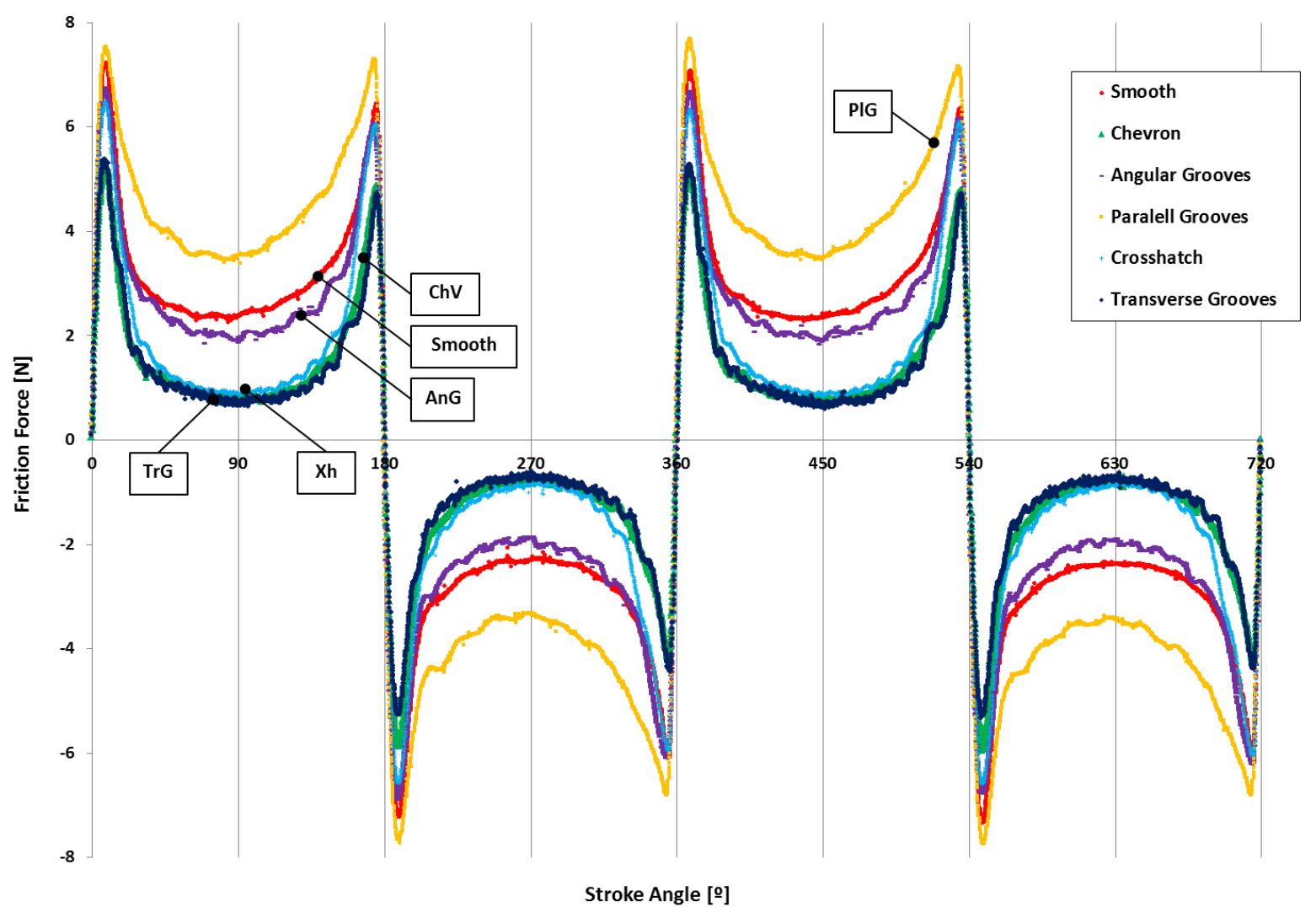

Figure 8 - Friction force comparison between all textured and non-textured samples under the boundary lubrication regime (test conditions: crank angular velocity: $180 \mathrm{rpm}$, normal load: $50 \mathrm{~N}$, oil temperature: $80^{\circ} \mathrm{C}, \lambda_{\text {smooth mid-stroke }}=0.9$ ). 
Figure 6, showing test results where oil viscosity was held constant at $273.6 \mathrm{mPa}$, clearly illustrates the full film lubrication regime (i.e when the lambda value for the smooth specimen at mid stroke is $\lambda_{\text {smooth, mid-stroke }}=6.4$ ), where the bearing remains lubricated along the entire length of the stroke. It can be observed that, as opposed to the boundary lubrication regime (Figure 8), the friction force increases towards the middle of the stroke. Without taking into account the spikes at reversal in the case of test pads $\mathrm{Xh}$ and $\mathrm{TrG}$, which are due to reverse motion taking place on a pocketed area (as discussed in Section 6.5), all the tested texture shapes present the highest friction mid-stroke, in the exact location where the sinusoidal sliding velocity has the highest value. This is explained by the fact that, in full film lubrication regime, friction force is created by the shearing between the oil layers inside the contact - as a result, the higher the velocity, the higher the friction force (note: film thickness also increases with velocity and thus acts to reduce friction, however this effect is outweighed by the increase in lubricant shear).

When performing tests close to the mixed lubrication regime $\left(\lambda_{\text {smooth, mid-stroke }}=2.2\right)$, friction force had its highest value immediately after reversal, probably due to the squeeze film effect [27], and decreases greatly after that. As depicted in Figure 7, a central plateau of almost uniform friction force is achieved along a large portion of the reciprocating stroke. This suggests a complete fluid film had formed, since well-established EHL theory predicts that traction does not vary strongly as a function of velocity.

In contrast to the full film regime, the boundary lubrication regime $\left(\lambda_{\text {smooth, mid-stroke }}=0.9\right)$, shows friction force to be at its highest values at the ends of the stroke (Figure 8), where, due to insufficient lubricant entrainment, friction is dominated by asperity contact. Friction decreases towards the middle of the reciprocating stroke, as the increasing sliding velocity acts to entrain more oil between the surfaces reducing asperity contact.

When investigating the effect of surface texture within the sliding contact and comparing the performance of various texture patterns against a smooth specimen, the experimental study shows that the impact of surface texture on friction force varies between the three regimes.

Under full film conditions, all surface textures tested gave a higher friction force - Figure 6 suggests that the plain pad is advantageous compared to any of the textured specimens. Friction force was significantly higher for test pads $\mathrm{Xh}$ and $\mathrm{TrG}$ when compared to the non-textured sample; however, a close match between friction curves for all five textured specimens is observable, with a minimal improvement in the case of pad AnG, which exhibits the lowest friction.

With regard to the friction force measurements near the mixed regime $\left(\lambda_{\text {smooth, mid-stroke }}=2.2\right)$, textured specimens $\mathrm{Xh}, \mathrm{ChV}$ and $\mathrm{TrG}$ showed marginally superior performance when compared to the reference smooth pad. However, Figure 7 suggests increased improvements for the pocketed surfaces towards both ends of the stroke. A $62 \%$ reduction in average friction force along one cycle was observed when comparing the best performing pocketed specimen, $\operatorname{Tr} G$, with the plain sample.

Finally, when the bearing was running in boundary lubrication regime, friction reductions of up to $51 \%$ were observed (when comparing the laser surface textured samples with the smooth reference), with chevron and transverse grooves patterns displaying the highest performance. Friction force is also significantly decreased by the textured patterns on test pads $\mathrm{Xh}$ and AnG, whilst pad PlG appears to be only instance resulting in higher friction force than in the case of the plain specimen.

Figure 9 compares the friction force under each of the regimes, given by the textured pad with grooves normal to the direction of sliding ( $\operatorname{TrG}$ ). Close to mid-stroke it is clear that friction is lowest when the contact is the close to mixed regime. 


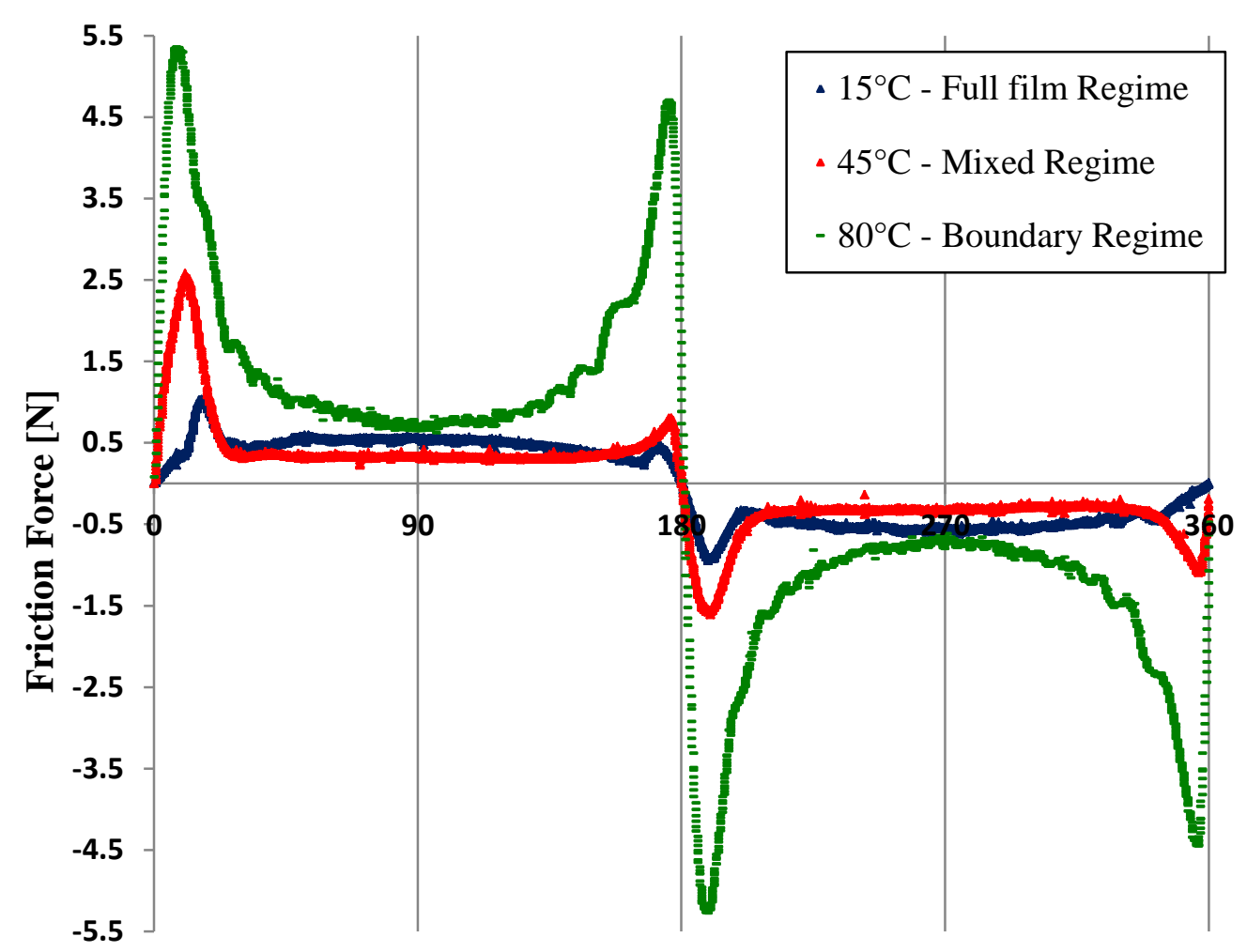

Crank Angle $\left[^{\circ}\right]$

Figure 9 - Three forms of friction force measured in the reciprocating test rig using a textured specimen with grooves orientated transversal to the direction of sliding (crank angular velocity: $180 \mathrm{rpm}$, normal load: $50 \mathrm{~N}$ ).

\subsection{Variation of power loss for different surface texture shapes}

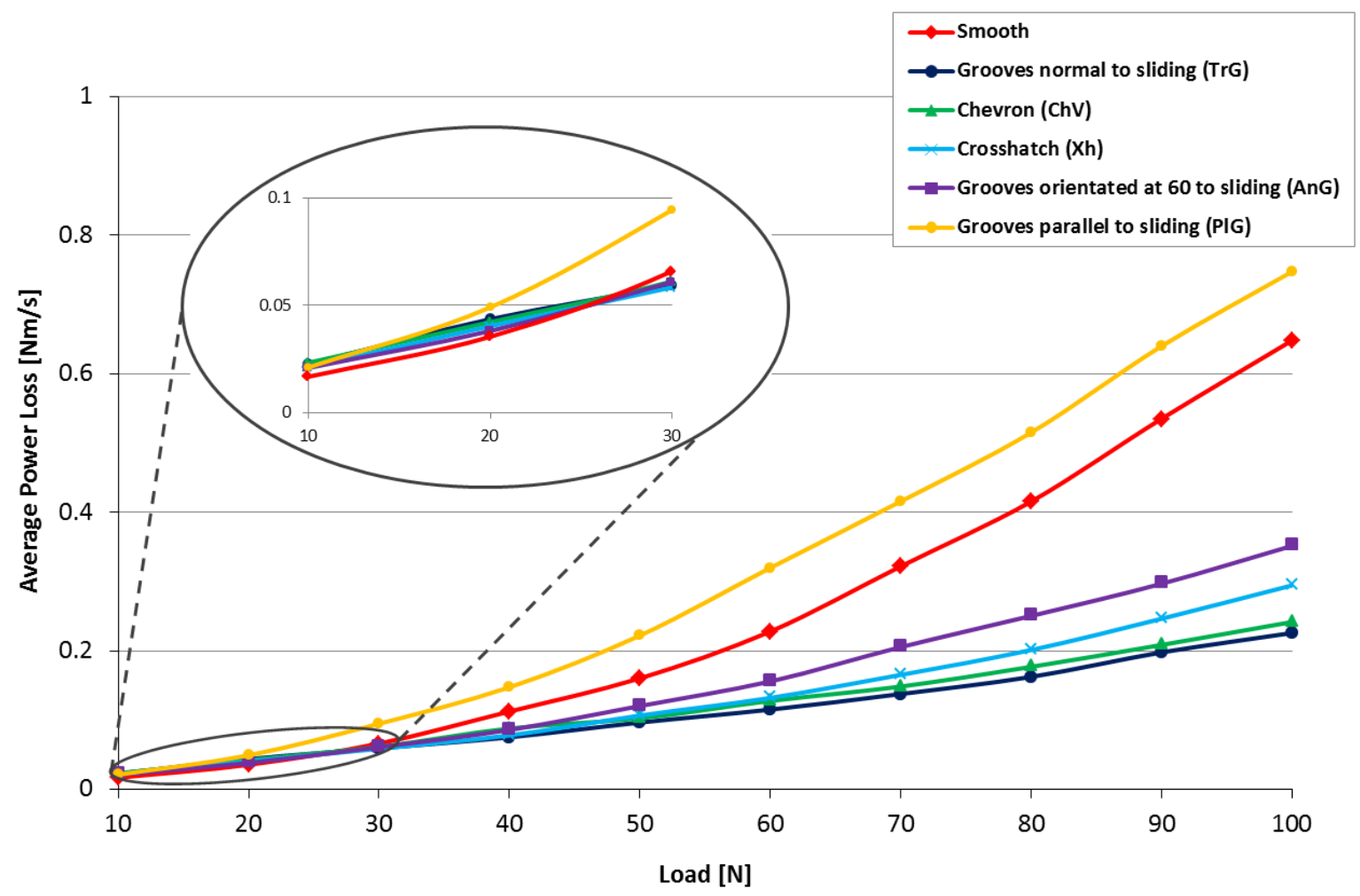

Figure 10 - Average power loss variation vs. load for all textured and non-textured fused silica specimens (test conditions: crank angular velocity: $240 \mathrm{rpm}$, oil temperature: $60^{\circ} \mathrm{C}$ ) 
The effect of the various patterns can be observed in Figure 10 where average power loss values for one complete cycle are plotted against applied normal load. Power loss in a reciprocating bearing as a result of bearing friction can be expressed as:

$$
P=F U
$$

where $F$ is the friction force and $U$ the speed of the moving surface. Tests were carried out at a higher crank angular velocity of $240 \mathrm{rpm}$, while the oil temperature was maintained at $60^{\circ} \mathrm{C}$ (oil viscosity: $35.095 \mathrm{mPa} . \mathrm{s})$.

This is consistent with the observations presented in Figures 6-8, where increasing reductions in friction are observed as the applied load increases and the contact is shifted from the full film to boundary, passing through the mixed lubrication regime. Furthermore, at relatively low loads, between 20 and $30 \mathrm{~N}$, there is almost no difference between the textured specimens and the smooth reference pad, the latter actually performing best when a 10 to $25 \mathrm{~N}$ normal load is applied. However, as the load increases, significant differences between the smooth sample and different patterns emerge, improvements in average power loss of up to $55 \%$ being recorded when comparing the plain sample with the transverse grooves pad over the entire range of applied loads.

In the mixed (Figure $7-\lambda_{\text {smooth, mid-stroke }}=2.2$ ) and boundary (Figure $8-\lambda_{\text {smooth, mid-stroke }}=0.9$ ) regimes, experimental pad $\operatorname{TrG}$ proved to be the best performing textured pattern over the entire range of normal loads ( 40 to $100 \mathrm{~N}$ ), closely followed by the chevron pattern. Table 3 summarizes the percentage reductions in average power loss for all textured patterns tested when compared with the plain reference, for the entire range of normal applied loads, $10-100 \mathrm{~N}$.

Sample shape

\begin{tabular}{|c|c|c|c|c|c|}
\hline & Crosshatch & Chevron & $\begin{array}{l}\text { Angular } \\
\text { Grooves }\end{array}$ & $\begin{array}{l}\text { Parallel } \\
\text { Grooves }\end{array}$ & $\begin{array}{c}\text { Transverse } \\
\text { Grooves }\end{array}$ \\
\hline $\begin{array}{c}\text { Average Percentage } \\
\text { Decrease/Increase }\end{array}$ & $-47 \%$ & $-52 \%$ & $-38 \%$ & $+25 \%$ & $-55 \%$ \\
\hline
\end{tabular}

Table 3 - Percentage change in average power loss along the entire range of applied normal loads $(10-100 \mathrm{~N})$

\subsection{The effect of the contact width to features width ratio and of the pattern orientation}

The specimens containing grooves orientated at $60^{\circ}$, normal and parallel to the sliding direction (Figure 11) were employed to investigate the effects of pattern orientation relative to direction of travel. The associated fiction comparisons can also be observed in Figures 6-8 and Figure 10, for all lubrication regimes. 


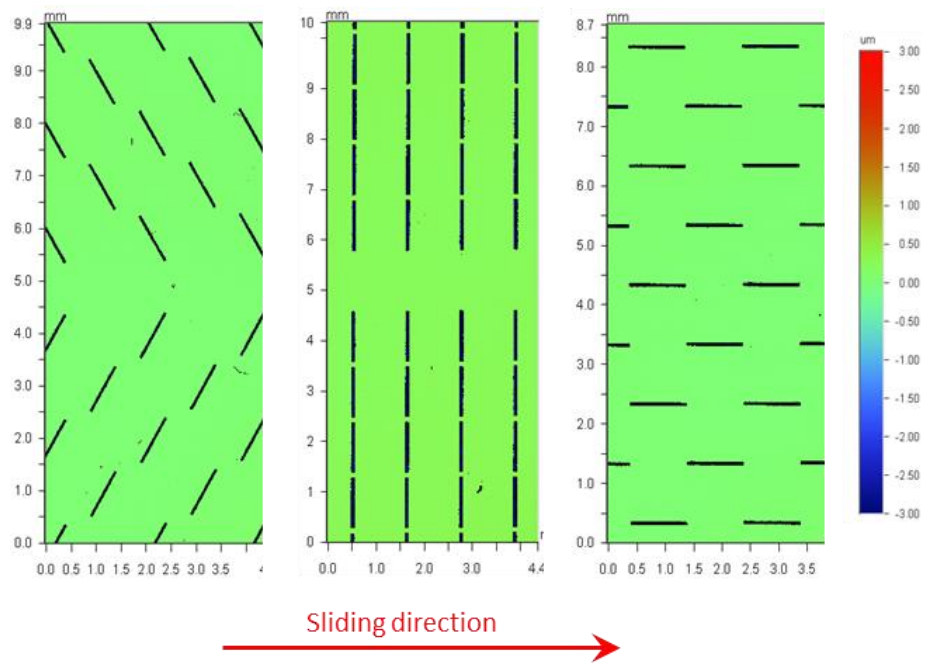

Figure 11 - Two dimensional surface plots of fused silica specimens exemplifying the relative orientation of grooves in relation to the direction of sliding.

Under low temperature full film conditions, there was no significant difference in friction between the different pattern orientations: however, in both the mixed and boundary regimes the test results clearly displayed that grooves orientated perpendicular to the direction of sliding (sample $\operatorname{TrG}$ ) showed the most beneficial friction behaviour, for all test conditions (crank angular velocities, oil temperatures and applied loads). The sample with grooves parallel to the sliding direction (sample PlG) exhibited the worst performance in all tests, being the only textured pattern with average friction values per cycle higher than the smooth specimen. The $60^{\circ}$ angled grooves pattern (sample AnG) performed significantly better over the whole range of tested loads, when compared with the plain and parallel grooves specimens, but considerably worse than the normal oriented grooves $(\mathrm{TrG})$.

These results may be explained by the fact that, if grooves are longer than the contact zone in the sliding direction (as on samples $\mathrm{AnG}$ and $\mathrm{PlG}$ ), pockets will have a tendency to allow high pressure oil to leave the contact zone, resulting in the oil film collapsing. This will inhibit oil film building after reversal and hence reduce the film thickness throughout the stroke, causing a higher shear rate in the oil film and increased asperity contact. Not only are friction losses increased and load support capability reduced, but this approach also results in higher wear rates. This is in agreement with both Costa et al. [22] and Pettersson et al. [28] who previously studied the effects of pattern orientation and suggested that, especially for higher normal loads, grooves parallel to the sliding direction give higher friction forces and lower oil film thicknesses when compared with transverse grooves.

In contrast, if the texture has individual features that have dimensions smaller than that of the contact zone, they will be entirely contained within the conjunction for a period during their transit and little pressure-induced flow is possible. This is the case, for example, with grooves positioned normal to the direction of travel ( $\mathrm{TrG})$. 


\subsection{Influence of texture at reversal}

If the location of the mid-stroke and the stroke length of a reciprocating bearing are known, the question arises as to where along the stroke should the texture be applied in order to minimise the friction. For instance, the texture could cover the entire sliding distance, be positioned only along the central region, or towards the end of the stroke. The current research suggests the latter case is optimal since this is where the contact will be operating in the boundary regime, however, it is possible that texture may have undesired effects if it positioned very close to reversal. Defining the optimal position of texture in this way is important since it can enable the maximum reduction in friction for the minimum manufacturing cost.

In order to study the influence of texture location on friction, reciprocating sliding tests were performed on two textured specimens, both with a pattern of grooves perpendicular to the sliding direction (pattern $\mathrm{TrG}$ ). The first fused silica sample (E1) had pockets only in the central region, (over $22.6 \mathrm{~mm}$ out of the $28.6 \mathrm{~mm}$ stroke length), leaving a smooth $3 \mathrm{~mm}$ area at each end (Figure 12 (a)). The second specimen (E2) had texture along the entire sliding distance, the reversal taking place exactly on a row of pockets, as depicted in Figure 12 (b). The two images, captured at the end of the reciprocating stroke, shown in Figure 12 (a) and (b), were obtained using an optical interferometry technique which allows the visualisation of the contact between the steel pad and the transparent silica specimen coated with a thin semi-reflective chromium layer. The images display two "dark" zones, one showing the contact area and the other a laser etched pocket, as well as fringes visible outside the contact, representing optical interference caused by varying fluid film thickness.

Figure 12 (c) shows that, while both friction curves closely follow the sinusoidal velocity profile, sample (E2), where the reversal takes place on a row of rectangular pockets, displays a significant spike in friction, immediately after reversal. This spike in friction ultimately leads to a $13 \%$ increase in the average friction force per stroke, when comparing case (E2) with (E1). 

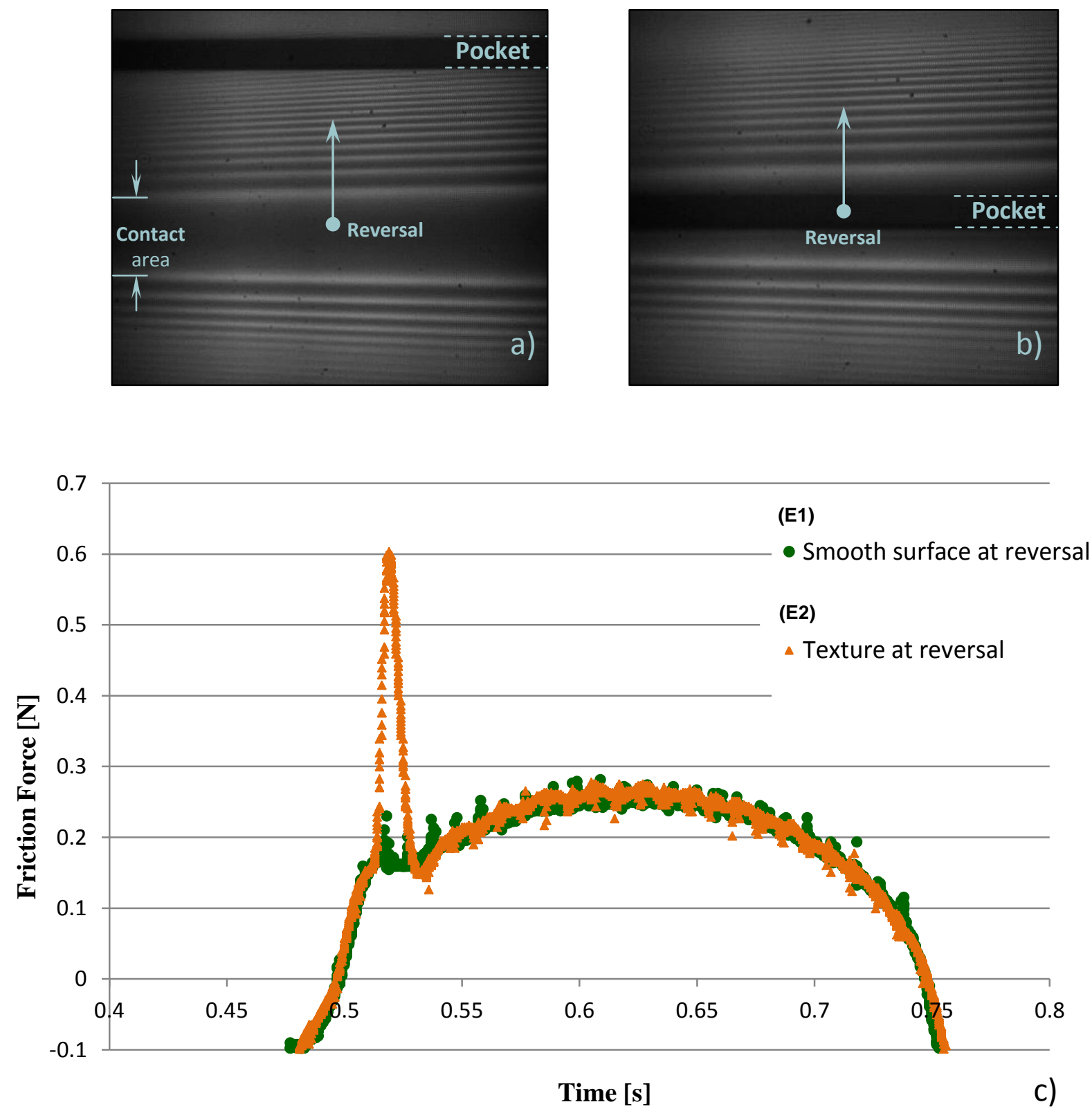

Figure 12 - Influence of texture at reversal: a) Optical image showing texture restricted to the central region reversal takes place on a smooth area; b) Optical image showing texture applied on the entire sliding distance reversal takes place with a pocket inside the contact area; c) Friction force profile variation for the same textured specimen (Transverse Grooves) under two different scenarios: (E1) reversal takes place on a smooth surface at the end of the stroke; (E2) reversal takes place on a line of pockets at the end of the stroke.

If pockets are located at one end of travel and protrude outside the contact, they can act to collapse the oil film, as shown in Figure 12. Therefore, to maximise the benefit of the pockets, there should be no pockets at the reversal position. However, as presented previously when assessing the mixed and boundary regimes, pockets close to reversal are beneficial in reducing friction by helping to build the oil film shortly before and after reversal point (see Figure 7).

\subsection{Influence of sliding velocity on friction force}

Figure 13 shows friction force for the best performing pocketed specimen ( $\operatorname{TrG})$ and the smooth reference pad plotted against sliding velocity, for each lubrication regime (note: this is the same data as shown in Figures 6-8, but plotted differently - similar to the film thickness vs. speed 
graphs obtained by Costa et al. [22]). As expected, these plots have the form of Stribeck curves, but are asymmetrical with respect to increasing and decreasing speed. This difference is due to squeeze film effects, which act to reduce changes in film thickness as the pad accelerates and decelerates. This agrees with observations of film thickness by Costa et al. [22] which were similarly asymmetric with respect to acceleration direction. It is interesting to note the effect of the squeeze film on friction is most pronounced in the mixed regime, as opposed to the full film regime where increasing and decreasing speed of the smooth pad show identical friction (Figure 13(a)). These plots further confirm the conclusions from Figures 6-8 that friction reduction occurs only in the boundary and mixed regimes and that the texture at reversal is detrimental (Figure 13(a)). Furthermore, Figure 13(b) seems to show that the textured specimen enters the full film regime at a lower speed that than the smooth specimen, which suggests that the effect of texture is to boost entrainment.

It is also interesting to note that the difference in friction between the textured and smooth pad remains constant over most of the speed range (Figure 13(c)). This is mainly because the contact is so far into the boundary regime and it is only in the mixed/full film regime that the results converge.
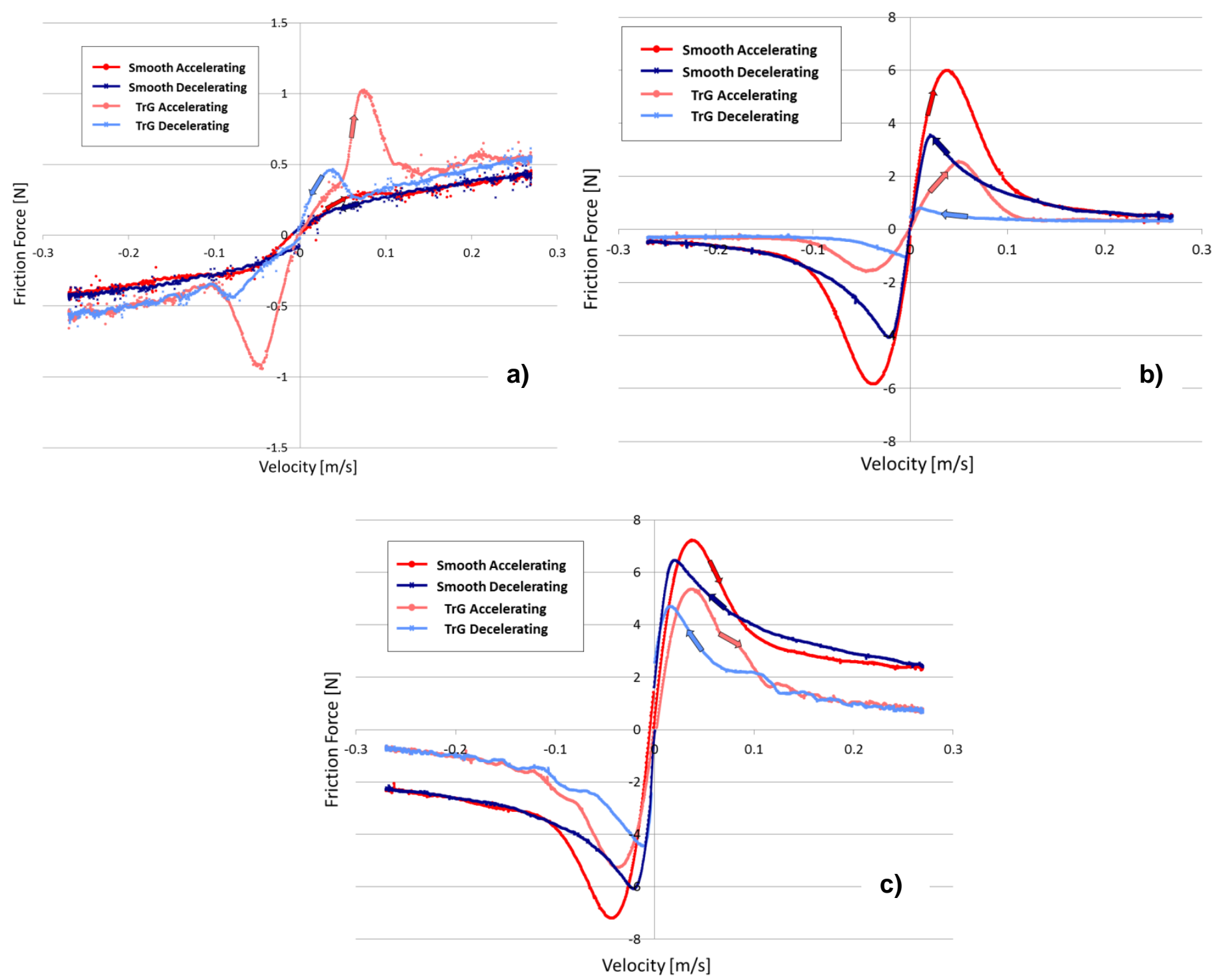

Figure 13 - Friction force profile variation between accelerating and decelerating portions of the stroke for both a smooth specimen and a textured one: (a) full film lubrication regime - oil temperature $15^{\circ} \mathrm{C}$; (b) mixed lubrication regime - oil temperature $45^{\circ} \mathrm{C}$; (c) boundary lubrication regime - oil temperature $80^{\circ} \mathrm{C}$. 
From each plot in Figure 13, it can be seen that, above a certain speed, the friction when accelerating equals that when decelerating. Under these conditions, (which correspond to crank angles between $30^{\circ}$ and $150^{\circ}$ ), it can be assumed that squeeze film effects are negligible. These portions of friction data can therefore be plotted again speed $\times$ viscosity in order to produce a master Stribeck curve, as shown in Figure 14. Here, results for both the smooth and the textured specimen with grooves normal to the sliding direction ( $\mathrm{TrG}$ ) are plotted, along with corresponding best fit lines, approximated by fitting a sigmoid functions to the data. This figure shows even more clearly that the textured specimen outperforms the smooth specimen in the boundary and mixed regime, but is detrimental when a full film separates the surfaces. It can also be argued that the effect of surface texture on the TrG specimen is to shift the Stribeck curve to the left (compared to the smooth specimen), possibly suggesting enhanced fluid entrainment.

It should be noted that all these results were obtained under piezo-viscous elastic conditions. It is possible that the effect of texture on friction under full film conditions may be different to those shown here, if the contact were operating in another lubrication regime, such as iso-viscous rigid. This issue will be the subject of further work.

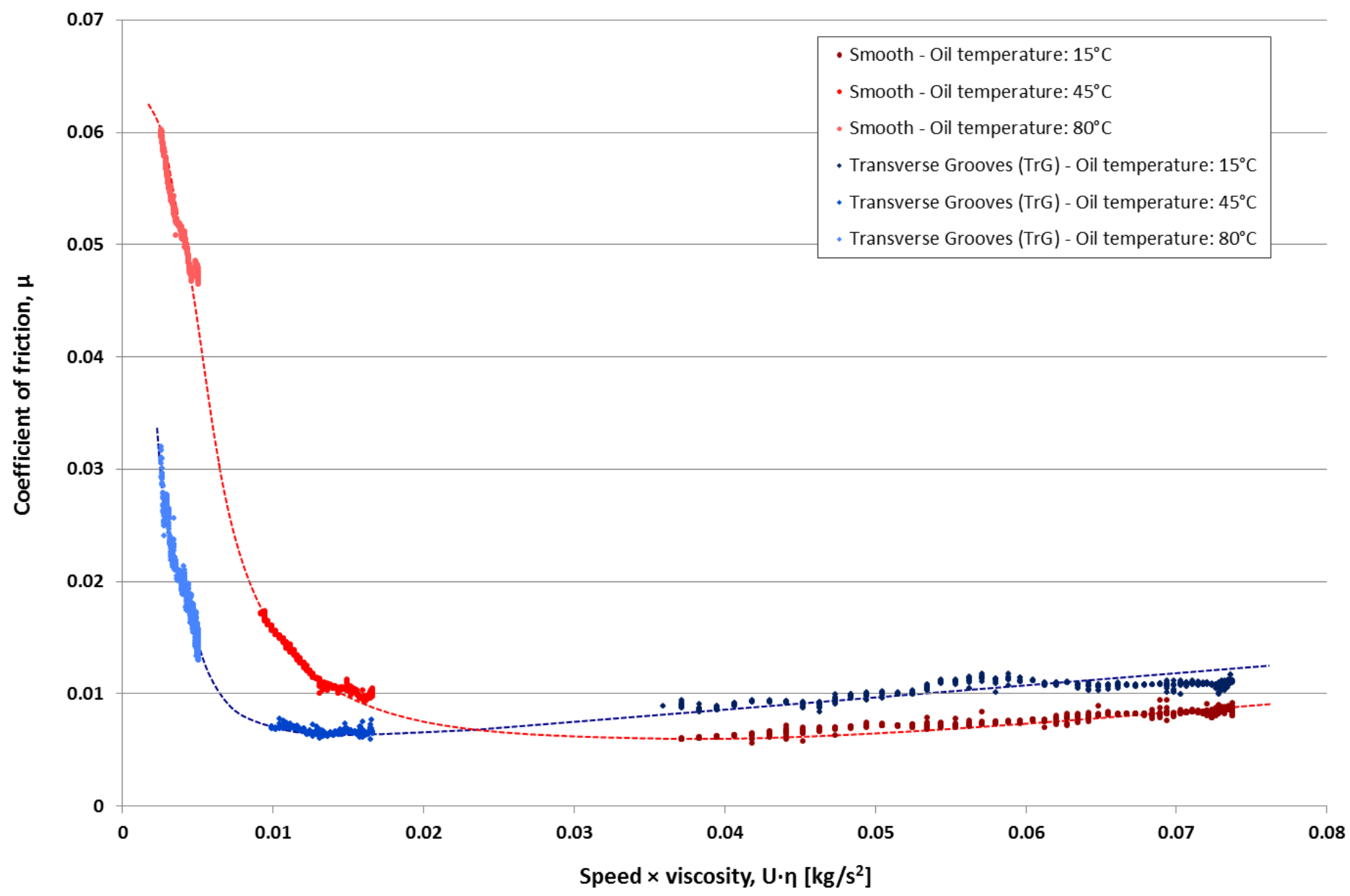

Figure 14 - Stribeck curves showing friction behaviour for the three lubricant temperatures used in this study: $15^{\circ} \mathrm{C}$, $45^{\circ} \mathrm{C}$ and $80^{\circ} \mathrm{C}$ 


\subsection{Influence of load and texture on cavitation}

Finally, a $2 \%$ mass concentration of a commercially available oil tracer dye was mixed into the fully formulated oil. Then, by employing the LIF microscope system, fluorescent images of the smooth bearing were captured, for a range of normal loads.

The qualitative results obtained in this way offer clear visualisation of the cavitation from the reciprocating contact. Figure 15 shows the presence of 6 to 7 cavitation bubbles at an applied load of $10 \mathrm{~N}$. Then, as the load increases to $20 \mathrm{~N}$ and $40 \mathrm{~N}$, the number of cavitation striations increases to ca. 11-13 and 34-38 respectively. For the maximum applied load of $80 \mathrm{~N}$, between 70 and 80 different cavitation striations are recorded on the same $0.8 \mathrm{~mm}$ length of the contact. This variation of cavitation streamers per unit length for different applied load conditions is in good agreement with analyses made by Dowson and Taylor [29-30] that, as minimum film thickness declines with load, the number of cavitation streamers consequently increases.

These results highlight the possibility of using the current experimental setup to study the effect of oil properties (such as surface tension) on cavitation behaviour.

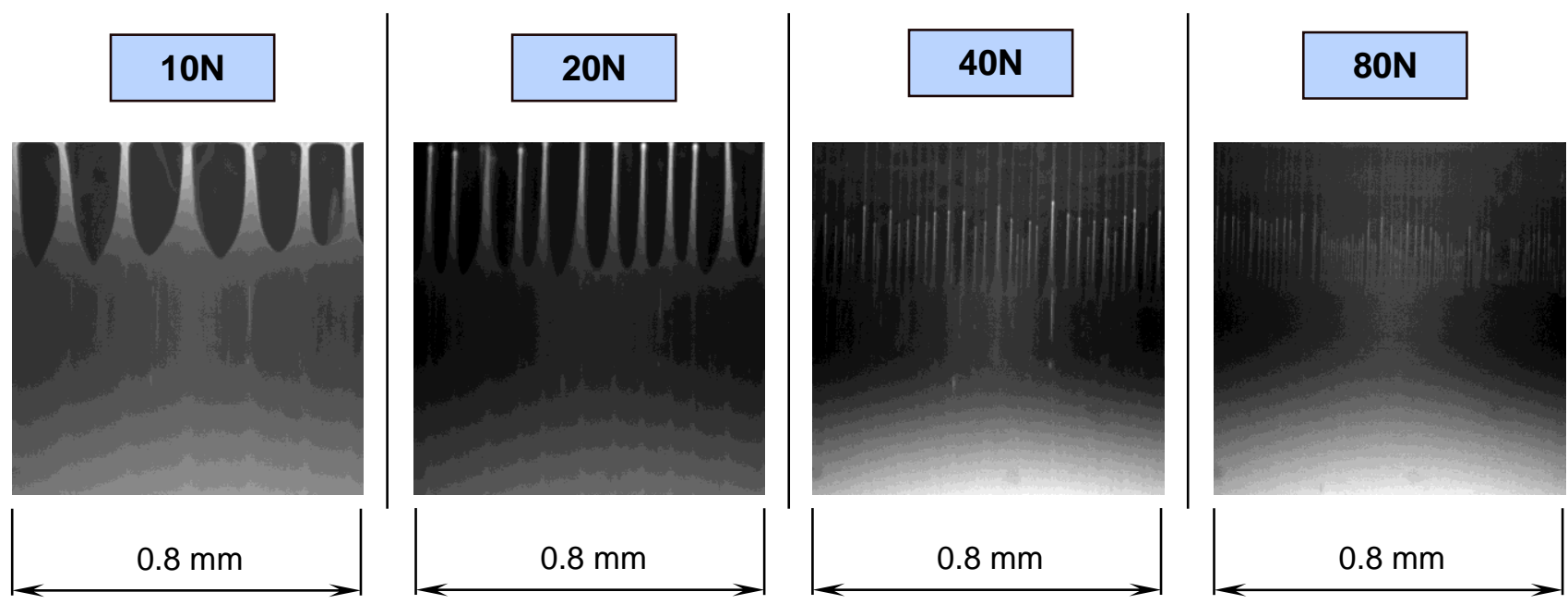

Figure 15 - Cavitation pattern variation for different applied loads

Furthermore, the trigger system enabled the response of the cavitation pattern to individual silica pad texture features to be imaged, as a single textured region passes through contact. Figures 16 (a) to $16(\mathrm{c})^{1}$ give a set of fluorescent images of a pocket passing through the contact, captured at each 0.7 degree of crankshaft revolution using test pads $\mathrm{AnG}, \mathrm{PlG}$ and test pad $\mathrm{ChV}$, respectively.

In all three cases, once the pocket emerges from the cavitated region it is seen to transfer fluid back into this region.

This observation suggests that in the full film lubrication regime, where friction is given by the shearing of the lubricant, textured specimens will give higher friction when compared with a plain one due to increased amounts of lubricant shear. This agrees with results shown in sections 6.1-6.2. Conversely, in mixed and boundary lubrication regimes, the cavitated region may reduce lubricant entrainment immediately after reversal. Therefore, pockets that bring oil into the cavitated region may aid lubricant entrainment and hence reduce friction under these conditions. This is in agreement with results shown in Figure 7 immediately after reversal.

This hypothesis is tentative and further investigation of the effect of surface texture on cavitation will be the subject of ongoing work. Furthermore, it is not suggested that this is the only

${ }^{1}$ In Figures 16(a)-16(c), x equals a particular value of the crankshaft's position, in degrees 
mechanism by which surface texture affects friction. In the boundary and mixed regime, it is also possible that the Tripp effect [31] (i.e. lubricant being squeezed out of the pocket due to elastic deformation of the component in the contact region) plays an important role.
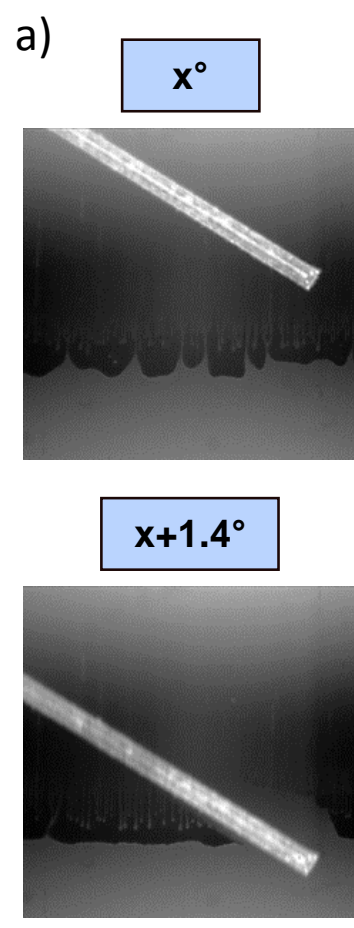

b)
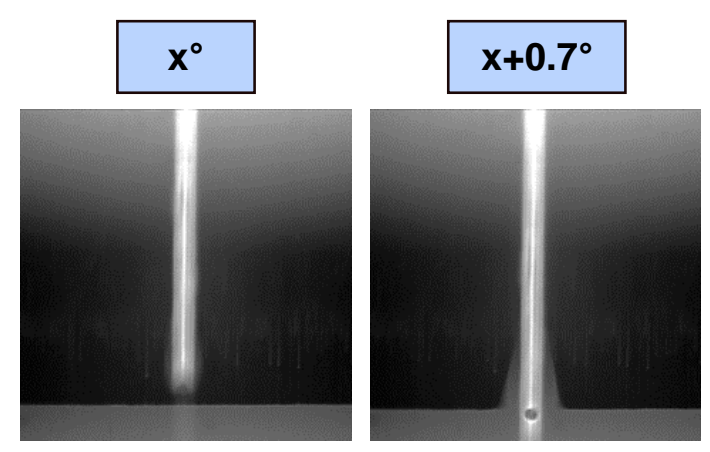

c)
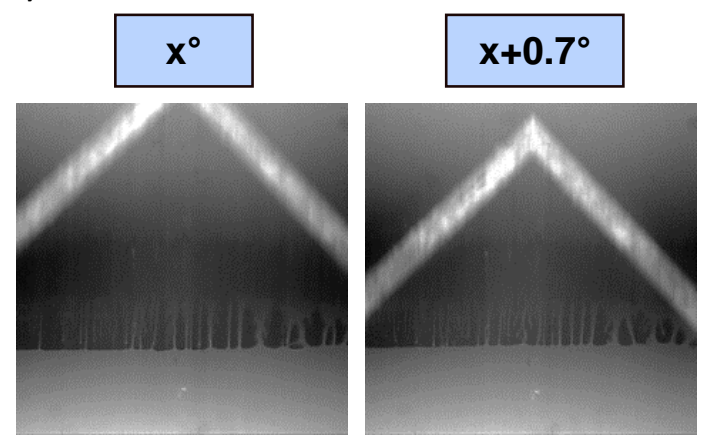

\section{$x+2.8^{\circ}$}

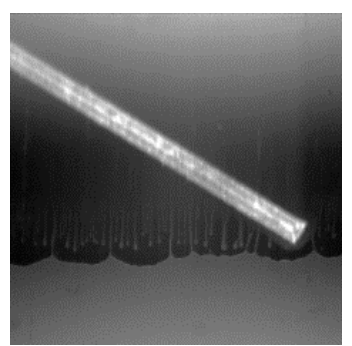

$x+2.1^{\circ}$
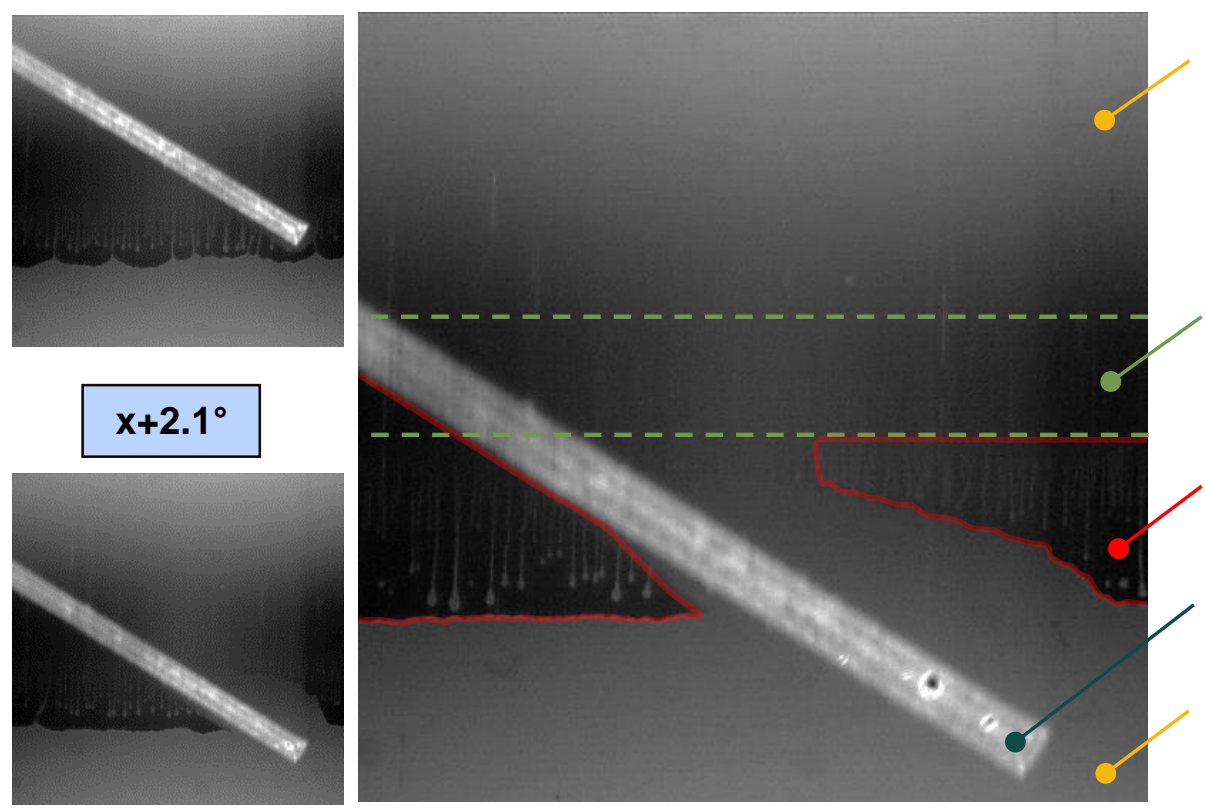

Contact

area

Cavitated

region

Pocket

Fluorescent

Oil - Outlet

u . 


\section{Conclusions}

This study aimed to make key steps in understanding how various surface texture patterns can influence bearings performance and, more importantly, under which lubrication conditions texture can be most advantageous. To achieve this, a new test apparatus has been developed to measure friction force in a convergent-divergent bearing. Using this apparatus, five textured specimens, with different pocket shapes, were assessed and compared with a smooth reference specimen. Test conditions were varied in order to place the bearing under different lubrication regimes. Reciprocating sliding tests revealed that surface texture can have either beneficial or detrimental effects on friction reduction depending on which lubrication regime the contact is operating in. Significant observations include:

- In low film thickness contacts, surface texture can improve friction performances along the entire length of the stroke. Reductions in friction of more than $50 \%$ were achieved when operating in the boundary lubrication regime, the textured pad with grooves perpendicular to the sliding direction being the top performer. It can be concluded that, as the lubricant film decreases and consequently directs the bearing towards the mixed lubrication regime, laser surfaced textures becomes increasingly beneficial, demonstrating the greatest reduction in friction when the bearing operates in the boundary lubrication regime. Conversely, as observed when analysing the pocketed surface with grooves parallel to the direction of sliding (PlG), texture can in fact be detrimental along the entire length of the Stribeck curve, when compared with a smooth, non-textured specimen.

- Surface texture can alter the performance of the convergent-divergent bearing when running in thick film friction contacts. In this full film lubrication regime, the reference smooth specimen achieved the lowest average friction along one full cycle.

- Although the friction force does not vary considerably along the central stroke plateau when running in mixed regime, surface texture shortly after reversal can significantly reduce the friction by helping to build the oil film within a shorter distance from the reversal point.

- Textured samples with pockets which can be entirely trapped in the contact zone (e.g. $\mathrm{TrG}$ ) performed better than textured samples comprising pockets longer than the contact zone in the direction of travel (e.g. Xh, AnG), the latter having the tendency to collapse the oil film by allowing the pressurized oil to escape from the contact zone. As a consequence, pattern orientation is essential when pockets are larger than the contact width.

- Surface texture at the end of travel can act to collapse the oil film. High friction spikes were observed when pockets were present along the entire stroke and consequently at the point of reversal. Hence, to maximise the benefits of surface texture, there should be no pockets at the reversal point.

- Asymmetries in friction variation between the samples' acceleration and deceleration zones were detected predominantly in the mixed regime, whereby the friction is higher when the samples were accelerating, as a consequence of the squeeze film effect occurring shortly after reversal.

- Of all textured shapes tested in this study, grooves perpendicular on the direction of sliding showed the highest level of effectiveness for all mixed and boundary regime tests, closely followed by the chevron pattern. Grooves parallel to the sliding direction were 
the least effective, performing worse than the smooth reference pad in all three lubrication regimes.

In ongoing research, the current experimental set up will be used to characterise the effect on friction reduction of pocket geometry (depth, width, density). Furthermore, film thickness will be combined with friction mechanisms in order to understand the friction reduction mechanisms more clearly.

\section{References}

1. Fontaras, G. and Z. Samaras, On the way to $130 \mathrm{~g}$ CO2/km-Estimating the future characteristics of the average European passenger car. Energy Policy, 2010. 38: p. 1826-1833.

2. EU, 2009. Regulation (EC) No. 443/2009 of the European Parliament and of the Council of 23 April 2009 setting emission performance standards for new passenger cars as part of the Community's integrated approach to reduce $\mathrm{CO} 2$ emissions from light-duty vehicles. Official Journal of the European Union.

3. Holmberg, K., P. Andersson and A. Erdemir, Global energy consumption due to friction in passenger cars. Tribology International, 2012. 47: p. 221-234.

4. Taylor, R.I. and R.C. Coy, Improved fuel efficiency by lubricant design: a review. Proceedings of the Institution of Mechanical Engineers, 2000. 214J: p. 1-15.

5. Hamilton, D.B, J.A. Walowit and C.M. Allen, A theory of lubrication by microirregularities. Transactions of ASME Journal of Basic Engineering, 1966. 88: p. 177-85.

6. Anno, J.N., J. Walowit and C. Allen, Microasperity lubrication. Journal of Lubrication Technology, 1968. 90: p. 351.

7. Tonder, K., Dynamics of rough slider bearings: effects of one-sided roughness/waviness. Tribology International, 1996. 29: p. 117-22.

8. Tonder, K., Hydrodynamic effects of tailored inlet roughness: extended theory. Tribology International, 2004. 37: p.137-42.

9. Etsion, I., Y. Kligerman and G. Halperin, Analytical and experimental investigation of laser-textured mechanical seal faces. Tribology Transactions, 1999. 42: p 511-6.

10. Ronen, A., I. Etsion and Y. Kligerman, Friction-Reducing Surface-Texturing in Reciprocating Automotive Components. Tribology Transactions, 2001. 44(3): p. 359-366.

11. Brizmer, V., Y. Kligerman and I. Etsion, A laser surface textured parallel thrust bearing. Tribology Transactions, 2003. 46(3): p. 397-403.

12. Kligerman, Y., I. Etsion and A. Shinkarenko, Improving tribological performance of piston rings by partial surface texturing. Journal of Tribology, 2005. 127(3): p. 632-638.

13. Etsion, I., State of the art in laser surface texturing. Transactions of ASME Journal of Tribology, 2005. 127: p. 248-253.

14. Fowell, M.T., S. Medina, A.V. Olver, H.A. Spikes and I.G. Pegg, Parametric study of texturing in convergent bearings. Tribology International, 2012. 52(0): p. 7-16.

15. Ausas, R., P. Ragot, J. Leiva, M. Jai, G. Bayada and G.C. Buscaglia, The Impact of the Cavitation Model in the Analysis of Microtextured Lubricated Journal Bearings. Journal of Tribology, 2007. 129(4): p. 868-875.

16. Ausas, R.F., M. Jai and G.C. Buscaglia, A Mass-Conserving Algorithm for Dynamical Lubrication Problems With Cavitation. Journal of Tribology, 2009. 131(3): p. 031702-031702.

17. Fowell, M., I. Pegg, A.V. Olver, A.D. Gosman and H.A. Spikes, Entrainment and Inlet Suction: Two Mechanisms of Hydrodynamic Lubrication in Textured Bearings. Journal of Tribology, 2006. 129(2): p. 336347.

18. Olver, A.V., M.T. Fowell, H.A. Spikes and I.G. Pegg, 'Inlet suction', a load support mechanism in nonconvergent, pocketed, hydrodynamic bearings. Proceedings of the Institution of Mechanical Engineers, Part J: Journal of Engineering Tribology, 2006. 220(2): p. 105-108.

19. Ryk, G.and I. Etsion, Testing piston rings with partial laser surface texturing for friction reduction. Wear, 2006. 261: p. 792-796.

20. Ryk, G., Y. Kligerman and I. Etsion, Experimental Investigation of Partial Laser Surface Texturing for PistonRing Friction Reduction. Tribology Transactions, 2005. 48: p. 583-588. 
21. Rahnejat, H., S. Balakrishnan, P.D. King and S. Howell-Smith, In-cylinder Friction Reduction Using a Surface Finish Optimization Technique. Journal of Automobile Engineering, 2006. 220: 1309

22. Costa, H.L. and I.M. Hutchings, Hydrodynamic lubrication of textured steel surfaces under reciprocating sliding conditions. Tribology International, 2007. 40: p. 1227-1238.

23. Etsion, I. and E. Sher, Improving Fuel Efficiency with Laser Surface Textured Piston Rings. Tribology International, 2009. 42: p. 542-547.

24. Podgornik, B. and M. Sedlacek, Performance, Characterization and Design of Textured Surfaces. Journal of Tribology, 2012. 134: p. 041701-1.

25. Brown, M.A., H. McCann and D.M. Thompson, Characterization of the Oil Film Behaviour Between the Liner and Piston of a Heavy-Duty Diesel Engine. SAE Technical Paper Series 932784, 1993

26. Johnson, K.L., Regimes of Elastohydrodynamic Lubrication. Journal of Mechanical Engineering Science, 1970. 12:9

27. Medina, S., M.T. Fowell, S.C. Vladescu, A.V. Olver and D. Dini, Transient Effects in Lubricated Textured Bearings. - in press

28. Pettersson, U. and S. Jacobson, Friction and wear properties of micro textured DLC coated surfaces in boundary lubricated sliding. Tribology Letters, 2004. 17(3): p. 553-9

29. Dowson, D. and C.M. Taylor, Cavitation in Bearings. Ann. Rev. Fluid Mech., 1979.11:p. 35-65

30. Taylor, C. M., Film Rupture for a Lubricated Cylinder Lightly Loaded against a Plane. Journal of Mechanical Engineering Science, 1974. 16:p. 225

31. Morales-Espejel, G.E., P.M. Lugt, J. Van Kuilenburg and J.H. Tripp, Effects of Surface Micro-Geometry on the Pressures and Internal Stresses of Pure Rolling EHL Contacts. Tribology Transactions, 2003. 46: p. 260-272 